UMEÅ UNIVERSITY MEDICAL DISSERTATIONS

NEW SERIES NO. 1508 ISSN 0346-6612 ISBN 978-91-7459-438-6

From the Department of Surgical and Perioperative Sciences Anesthesiology and Intensive Care and

Umeå University, Umeå, Sweden

\title{
Accidental hypothermia and local cold injury: physiological and epidemiological studies on risk
}

\section{Helge Brändström}

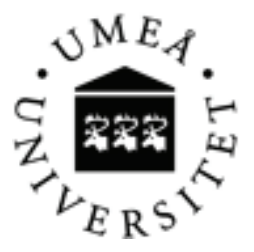

Umeå 2012 
Cover illustration from "SnowCrystals.com"

Copyright (C) 2012 Helge Brändström

ISBN 978-91-7459-438-6

Printed in Sweden by

Print Media, Umeå, 2012 


\section{"If the Lord Almighty had consulted me before embarking on creation, I should have recommended something simpler"}

Alphonso the Wise (1221-1289)

This work is dedicated to the memory of my parents, who provided a warm home for me and my brothers and sisters. 


\begin{abstract}

\section{Background:}

(Papers I and II) The objectives were to first determine incidence and contributing factors to coldrelated injuries in northern Sweden, both those that led to hospitalization and those that led to fatality. (Papers III and IV) A further aim was to assess post-cooling hand-rewarming responses and effects of training in a cold environment, both on fingertip rewarming and on function of the autonomic nervous system, to evaluate if there was adaptation related to prolonged occupational cold exposure.
\end{abstract}

\title{
Methods:
}

In a retrospective analysis, cases of accidental cold-related injury with hospital admission in northern Sweden during 2000-2007 were analyzed (Paper I). Cases of fatal hypothermia in the same region during 1992-2008 were analyzed (Paper II). A cohort of volunteers was studied before and after many months of occupational cold exposure. Subject hand rewarming response was measured after a cold hand immersion provocation and categorized as slow, moderate or normal in rewarming speed. This cold provocation and rewarming assessment was performed before and after their winter training. (Paper III). Heart rate variability (HRV) was analyzed from the same cold provocation/recovery sequences (Paper IV).

\section{Results:}

(Paper I) For the 379 cases of hospitalization for cold-related injury, annual incidences for hypothermia, frostbite, and drowning were $3.4 / 100,000,1.5 / 100,000$, and 1.0/100,000 inhabitants, respectively. Male gender was more frequent for all categories. Annual frequencies for hypothermia hospitalizations increased during the study period. Hypothermia degree and distribution of cases were $20 \%$ mild (between 32 and $\left.35^{\circ} \mathrm{C}\right), 40 \%$ moderate $\left(31.9\right.$ to $28^{\circ} \mathrm{C}$ ), and $24 \%$ severe $\left(<28^{\circ} \mathrm{C}\right)$, while $12 \%$ had temperatures over $35.0^{\circ} \mathrm{C}$. (Paper II) The 207 cases of fatal hypothermia showed an annual incidence of 1.35 per 100,000 inhabitants, $72 \%$ in rural areas, $93 \%$ outdoors, $40 \%$ found within 100 meters of a building. Paradoxical undressing was documented in $30 \%$. Ethanol was detected in femoral vein blood in $43 \%$. Contributing co-morbidity was common including heart disease, previous stroke, dementia, psychiatric disease, alcoholism, and recent trauma. (Paper III) Post-training, baseline fingertip temperatures and cold recovery variables in terms of final rewarming fingertip temperature and vasodilation time increased significantly in moderate and slow rewarmers. Cold-related injury (frostbite) during winter training occured disproportionately more often in slow rewarmers (4 of the 5 injuries). (Paper IV) At 'pre- winter-training', normal rewarmers had higher power for low frequency and high frequency heart rate variability. After cold acclimatization (posttraining), normal rewarmers showed lower resting power values for the low frequency and high frequency heart rate variability components.

\section{Conclusions:}

Hypothermia and cold injury continues to cause injury and hospitalization in the northern region of Sweden. Assessment and management is not standardized across hospitals. With the identification of groups at high risk for fatal hypothermia, it should be possible to reduce the incidence, particularly for highest risk subjects; rural, living alone, alcohol-imbibing, and psychiatric diagnosis-carrying citizens. Long-term cold-weather training may affect hand rewarming patters after a cold provocation, and a warmer baseline hand temperature with faster rewarming after a cold provocation may be associated with less general risk for frostbite. Heart rate variability results support the conclusion that cold adaptation in the autonomic nervous system occurred in both groups, though the biological significance of this is not yet clear.

Keywords: cold-related injuries, hypothermia, frostbite, cold adaptation, rewarming, autonomic nervous system, heart rate variability 


\section{ORIGINAL PAPERS}

This thesis is based on the following papers, which will be referred to in the text by their Roman numerals:

I Helge Brändström, Gordon Giesbrecht, Ola Winsö, Karl-Axel Ängquist, Michael Haney.

Accidental cold-related injury leading to hospitalization in northern Sweden (2000-2007).

Manuscript.

II Helge Brändström, Anders Eriksson, Gordon Giesbrecht, Karl-Axel Ängquist, Michael Haney.

Fatal Hypothermia: an analysis from a sub-arctic region.

Int. J of Circumpolar Health (E-pub ahead of print May 8, 2012)

III Helge Brändström, Helena Grip, Per Hallberg, Christer Grönlund, Karl-Axel Ängquist, Gordon G. Giesbrecht.

Hand Cold Recovery Responses Before and After 15 Months of Military Training in a Cold Climate.

Aviat Space Environ Med 2008; 79: 90 -8.

IV Helge Brändström, Urban Wiklund, Marcus Karlsson, Karl-Axel Ängquist, Helena Grip, Michael Haney.

Autonomic nerve system responses for normal and slow rewarmers after hand cold provocation: effects of long-term cold climate training.

Int Arch Occup Environ Health. Accepted and E-pub: 22 March 2012

The original papers have been reprinted with kind permission from the publishers. 


\section{CONTENTS}

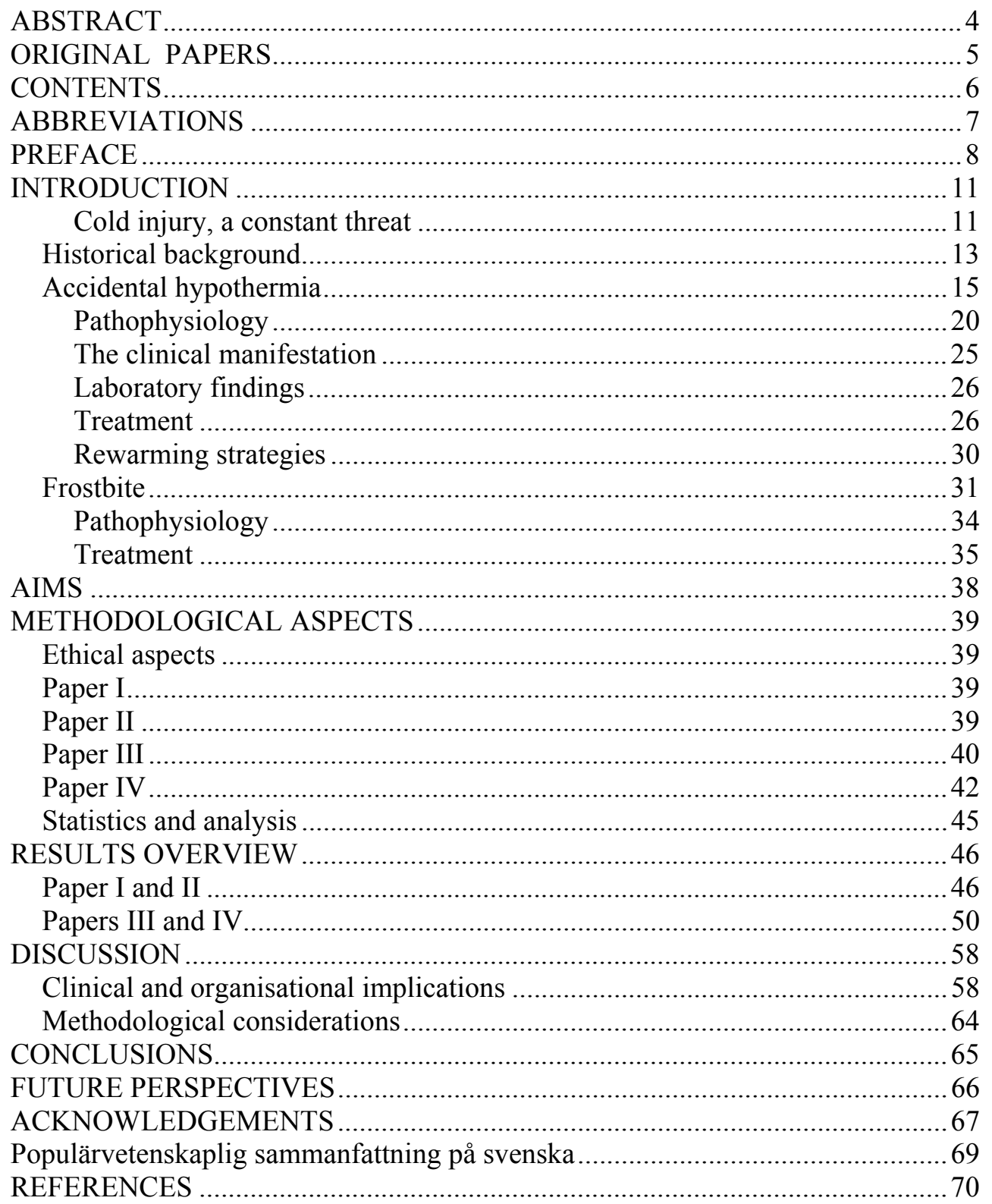




$\begin{array}{ll}\text { ABBREVIATIONS } \\ \text { ANOVA } & \text { analysis of variance } \\ \text { CAVR } & \text { continous arterio-venous rewarming } \\ \text { CDC } & \text { Centers for Disease Control and Prevention } \\ \text { CIVD } & \text { cold-induced vasodilation } \\ \text { CNS } & \text { central nervous system } \\ \text { CVVHD } & \text { continous venovenous hemofiltration and dialysis } \\ \text { ECG } & \text { electrocardiography } \\ \text { ECMO } & \text { extra corporeal membrane oxygenation } \\ \text { EEG } & \text { electro -encephalography } \\ \text { HF } & \text { high frequency } \\ \text { HR } & \text { heart rate } \\ \text { HRV } & \text { heart rate variability } \\ \text { ICD } & \text { International Classification of Diseases } \\ \text { IR } & \text { infra-red } \\ \text { KFI } & \text { kyla, fukt och immobilisering } \\ \text { LF } & \text { low frequency } \\ \text { NFCI } & \text { non-freezing cold injury } \\ \text { P } & \text { power } \\ \text { PG } & \text { prostaglandin } \\ \text { SMHI } & \text { Swedish Meteorological and Hydrological Institute } \\ \text { T } & \text { temperature } \\ \text { TXA } & \text { tromboxane } \\ \text { VD } & \text { vasodilation } \\ \text { VLF } & \text { very low frequency } \\ \end{array}$




\section{PREFACE}

\section{The Little Match Girl}

It was so terribly cold. Snow was falling, and it was almost dark. Evening came on, the last evening of the year. In the cold and gloom a poor little girl, bareheaded and barefoot, was walking through the streets. Of course when she had left her house she'd had slippers on, but what good had they been? They were very big slippers, way too big for her, for they belonged to her mother. The little girl had lost them running across the road, where two carriages had rattled by terribly fast. One slipper she'd not been able to find again and a boy had run off with the other, saying he could use it very well as a cradle some day when he had children of his own. And so the little girl walked on her naked feet, which were quite red and blue with the cold. In an old apron she carried several packages of matches, and she held a box of them in her hand. No one had bought any from her all day long, and no one had given her a cent.

Shivering with cold and hunger, she crept along, a picture of misery, poor little girl! The snowflakes fell on her long fair hair, which hung in pretty curls over her neck. In all the windows lights were shining, and there was a wonderful smell of roast goose, for it was New Year's eve. Yes, she thought of that!

In a corner formed by two houses, one of which projected farther out into the street than the other, she sat down and drew up her little feet under her. She was getting colder and colder, but did not dare to go home, for she had sold no matches, nor earned a single cent, and her father would surely beat her. Besides, it was cold at home, for they had nothing over them but a roof through which the wind whistled even though the biggest cracks had been stuffed with straw and rags.

Her hands were almost dead with cold. Oh, how much one little match might warm her! If she could only take one from the box and rub it against the wall and warm her hands. She drew one out. R-r-ratch! How it sputtered and burned! It made a warm, bright flame, like a little candle, as she held her hands over it; but it gave a strange light! It really seemed to the little girl as if she were sitting before a great iron stove with shining brass knobs and a brass cover. How wonderfully the fire burned! How comfortable it was! The youngster stretched out her feet to warm them too; then the little flame went out, the stove vanished, and she had only the remains of the burnt match in her hand.

She struck another match against the wall. It burned brightly, and when the light fell upon the wall it became transparent like a thin veil, and she could see through it into a room. On the table a snow-white cloth was spread, and on it stood a shining dinner service. The roast goose steamed gloriously, stuffed with apples and prunes. And what was still better, the goose jumped down from the dish and waddled along the floor with a knife and fork in its breast, right over to the little 
girl. Then the match went out, and she could see only the thick, cold wall. She lighted another match. Then she was sitting under the most beautiful Christmas tree. It was much larger and much more beautiful than the one she had seen last Christmas through the glass door at the rich merchant's home. Thousands of candles burned on the green branches, and colored pictures like those in the print shops looked down at her. The little girl reached both her hands toward them. Then the match went out. But the Christmas lights mounted higher. She saw them now as bright stars in the sky. One of them fell down, forming a long line of fire.

"Now someone is dying," thought the little girl, for her old grandmother, the only person who had loved her, and who was now dead, had told her that when a star fell down a soul went up to God.

She rubbed another match against the wall. It became bright again, and in the glow the old grandmother stood clear and shining, kind and lovely.

"Grandmother!" cried the child. "Oh, take me with you! I know you will disappear when the match is burned out. You will vanish like the warm stove, the wonderful roast goose and the beautiful big Christmas tree!"

And she quickly struck the whole bundle of matches, for she wished to keep her grandmother with her. And the matches burned with such a glow that it became brighter than daylight. Grandmother had never been so grand and beautiful. She took the little girl in her arms, and both of them flew in brightness and joy above the earth, very, very high, and up there was neither cold, nor hunger, nor fear- they were with God.

But in the corner, leaning against the wall, sat the little girl with red cheeks and smiling mouth, frozen to death on the last evening of the old year. The New Year's sun rose upon a little pathetic figure. The child sat there, stiff and cold, holding the matches, of which one bundle was almost burned.

"She wanted to warm herself," the people said. No one imagined what beautiful things she had seen, and how happily she had gone with her old grandmother into the bright New Year.

The Little Match Girl. A translation of Hans Christian Andersen's "Den lille Pige med Svovlstikkerne" by Jean Hersholt. Reproduced from the Hans Christian Andersen Center website (http://www.andersen.sdu.dk/index_e.html), managed by the University of Southern Denmark 


\section{INTRODUCTION}

\section{Cold injury, a constant threat}

Hypothermia and cold injury has always been a threat to well-being for mankind. We are vulnerable. If it is not absolutely perfect conditions in our environment then we need heat generation and protective clothing, insulation, to maintain our body temperature and function. In this work, we will only consider the human responses to cooler conditions, and not to warmer conditions. When environmental temperatures are low, and our own energy production and insulation are not adequate to maintain our body temperature, then we need shelter and external energy to protect us from heat loss and ensuing local cold injury or low body temperature, hypothermia. Prevention of hypothermia due to exposure has always been a central theme for human survival in challenging climates.

The importance of learning from experience

Some of the most notable general descriptions of medical conditions have come in classical literature, notably by Charles Dickens and others and an excellent description of a case of death by hypothermia is found in H. C. Andersen's 'The Little Match Girl'. H. C. Andersen's story is well known, and often read as a Christmas saga, but it is generally not recognized as an expert description of cold injury and hypothermic death. More recent and local descriptions on the threat of cold are to be found in our own region. In this introduction, I present several local events or cases of hypothermia and frostbite. These made such a strong impression on me, growing up and working in this region, that they also became a large influence on my research interests and focus on this topic. One or more of these cases are known to almost everyone of a certain generation in the area where I grew up and work.

In the Anaris accident on 24 February 1978, six healthy and well-equipped young skiers were on their way between two cabins up in the mountains in western Jämtland when they got caught in a blizzard with wind-speeds up to $20 \mathrm{~m} / \mathrm{s}$. With heavy snow drifting, loss of visibility, and low ambient temperature, they soon suffered from frostbite and exhaustion. They dug a ditch in the snow to try to make some shelter, though where they chose to dig the snow was only $80 \mathrm{~cm}$ deep. They did not recognize that 15-20 meters away the snow was 5-6 meters deep. Before the first day was over, three other people joined the group, so now they were 9 persons in the ditch, fighting for their lives. On the second day of the storm, the only person who ultimately survived tried to dig the others out of the snow with his bare hands. Not succeeding, he managed to walk four kilometres in the snow, back to the cabin from where they started. He contacted the police and the rescue service, who then found the rest of the group. Two of them showed signs of life and were evacuated by helicopter, one sitting, to the nearest hospital though neither of them survived. One question which struck me upon first learning 
about this incident- why did one victim survive, and why did the two who had signs of life, and were rescued from the site, die while in hospital?

On October 18, 2008, a 58 year old man canoeing in a river in western Lapland capsized, where the water temperature was $8-10^{\circ} \mathrm{C}$. He was able to swim to a small island, and from his cell phone sent an alarm to the rescue services. When they arrived, after rowing over to the island, they found him alive but semi-comatose. They decided to carry him over the somewhat rough terrain, put him in the boat, and row back to the shore, where an ambulance helicopter could land and then transport him to the nearest hospital. While rescue personnel carried him on the island, he suffered a cardiac arrest. Opon the victim's arrival to the ambulance helicopter, a medical team recognized that he was in cardiac arrest. They immediately started routine cardiopulmonary resuscitation and connected him to an automated chest compression device. He did not survive and death was attributed to severe hypothermia. Autopsy revealed several broken ribs and large volumes (litres) of blood in both pleura. What was the reason for this? Did he actually die from hypothermia or from internal bleeding or a combination of these? Did hypothermia affect his coagulation?

Cold in its extremes is always a threat to life even though we encounter treatment programs in hospitals which involve some degree of hypothermia as a form of temporary treatment which is thought to be protective of vital organs (Bernard 2009; Saukko 2004). Accidental and uncontrolled hypothermia and cold injury is not protective- it is injurious, and if not stopped in time and treated, it will be fatal.

How cold affects the human body

Man's ability to survive and maintain a constant body temperature at $37^{\circ} \mathrm{C}$ enables him to survive in different environments and over a wide range of environmental temperatures. Man is thermally neutral at approximately $27^{\circ} \mathrm{C}$, which means that at that ambient temperature, a healthy person at rest can maintain a constant body temperature at $37^{\circ} \mathrm{C}$ without clothing. (Rintamäki 2007). As soon as the environmental temperature is relatively low, homeostatic and temperature regulatory mechanisms are activated. Usually a person can maintain their body temperature through self-generated heat (without protective/insulating clothing) even with an environmental temperature down to approximately $15^{\circ} \mathrm{C}$, assuming that there is no wind (convective forces) and that the air is dry (Rintamäki 2007). When surrounding temperatures sink below $15^{\circ} \mathrm{C}$, physical activity must increase (heat generation), and protective/insulating clothing be worn in order to maintain normal body temperature.

Thermo-receptors in skin immediately sense a falling ambient temperature, and at the same time, central thermo-receptors in the spinal cord, abdominal viscera and in and around the great veins in the upper abdomen and thorax signal to the brain that there are changes in core body (blood) temperature (Guyton 2006). Both peripheral and central thermo-receptors provide afferent signals to spinal cord first 
and then to the body's temperature regulatory 'center' in the hypothalamus. When skin and core body temperature drop, there is a coordinated central response to limit further loss of body temperature (Guyton 2006), which first includes peripheral vasoconstriction that limits further heat loss through the skin. Heat production is increased by shivering. Shivering is a combination of synchronised and unsynchronised muscular contractions of both agonist and antagonist muscle groups. The intensity of shivering varies over time, triggered by a falling core temperature. Shivering is an unconscious autonomic answer to the need for extra heat production when core temperature falls. Injuries or illnesses can affect both the sensing (afferent) as well as the temperature-conserving (efferent) aspects of temperature regulation. If the input to the thermoregulatory system is inhibited or impaired, thermoregulation can be partly or wholly eliminated leaving a person without the appropriate protective mechanisms (De Witte and Sessler 2002).

When drug effects impair the circulatory regulation or limit peripheral vasoconstriction, then there is obligatory vasodilatation, even if this is contrary to the protective responses of a healthy body. The issue of peripheral vascular tone and response in hypothermia is complex. At times, when there is cold injury, it may seem that there is a paradoxical or maladaptive response. For example, in extreme cold and pre-terminally, there may be impaired vasoconstriction. There are many links in this system of afferent, central regulation, and efferent effectors which work for temperature preservation, and which must function in harmony if severe body cooling is to be prevented (Guyton 2006). The need for an intact sensor, central regulation, and effector system for temperature homeostasis is equally important in warm environments.

Cooling and cold are not the same thing. The term cooling technically refers to ambient temperatures under $15^{\circ} \mathrm{C}$, and cold refers to temperatures under freezing $\left(0^{\circ} \mathrm{C}\right)$. Hypothermia is the term for body temperature which, due to accident, illness, or iatrogenic causes, drops below $35^{\circ} \mathrm{C}$. The description of local cold injury depends on the temperature at which an injury was acquired: at ambient temperatures below $0^{\circ} \mathrm{C}$, it is called frostbite; at ambient temperatures above $0^{\circ} \mathrm{C}$, it is called non-freezing cold injury (NFCI) 'trench foot' (KFI-skador in Swedish, kyla, fukt, immobilisering) (Francis and Golden 1985).

How cold affects humans, which environmental or situational factors contribute to cold injury, possible predisposition or extreme temperature adaptation related to hypothermia, local cold injury and risk for hypothermic death, the process of accidental hypothermia in its extreme, and how we care for surviving, or potentially surviving, victims of extreme hypothermia are the questions which have been explored in my studies in this thesis.

\section{Historical background}

Hypothermia was described in ancient times by Hippocrates, Aristotle, and Galen, though without our modern insight into etiology and treatment. Treatment 
has historically been the subject of much debate (Paton 1983; Danzl 1988; Danzl et al 1998). Descriptions of cold injury and how it has affected human performance are perhaps best found in military historical documents. One of the oldest European descriptions was written by Xenophon, describing how the army of Cyrus the Younger, in $401 \mathrm{BC}$, suffered cold injury leading to massive casualties, and how Cyrus ordered amputations among the survivors in his army during an expedition from Sardis and over the Caucasian mountains (Armenia) to Babylon and back (Spelman 1749). It has been speculated that Alexander the Great may have fallen into a hypothermic coma during one of his campaigns over wintry mountains. Hannibal, in $218 \mathrm{BC}$, lost more than half of his 40000 strong army to cold injury during their march over the Pyrenees and then the Alps on their way to Podalen (Bangs and Hamlet 1983). Napoleon's army, which initially was more than 650,000 during his campaign into Russia, lost many to hypothermia during the siege of Moscow and his subsequent retreat. They were surrounded by a raw fog or haze, which coated their clothes with ice, thick as plates. They were forced to abandon their siege due to the cold, and their retreating army was reduced to 110,000 men, and only 2000 finally made it back to France. Thousands died along the way home, as a consequence of hypothermia and local cold injuries. Amputations were commonplace (Larrey 1832).

Napoleon's chief surgeon, Baron D. J. Larrey, initiated a treatment of rubbing the frostbite affected part with snow. "Should these remedies fail (e.g. rubbing the affected part with snow) the part ought to be plunged in cold water, in which it should be bathed, until bubbles of air are seen to disengage themselves from the congealed part. This is the process, adopted from the Russians, for thawing a fish. If they soak it in warm water, they know from experience that it will become putrid in a few minutes; whereas, after immersion in cold water, it is fresh as if it had just been caught" (Larrey 1832). This treatment idea survived, despite its wrong conception and deleterious effects, well into modern times (Greene 1942). One can read, in the Swedish Army Field reference from 1932, that 'Treatment for general cold injury should be bathing in ice-cold water...', and that for frostbite, treatment should be 'rubbing with snow until the warmth and sensation return'. In the Swedish Army order from 1958, under the category of 'Rules to remember for the field medic', one can read the following: 'Frostbite should be warmed up with massage, though not with snow.'

Modern treatment of cold injury using rewarming in warm water began first during the 1940's. This treatment was based on the successful experiments of the Russian scientist Ariev, during the 1930's, but never achieved general acceptance since his reports were written in Russian (Ariev 1940). It was first when a Dr. and Mrs. Fuhrman (Fuhrman and Crismon, 1947) began using this method that it came to be more broadly recognized. The real breakthrough came at the beginning of the 1960 's, when Dr. WJ Mills published the first large clinical report of hypothermia patients and treatment (Mills 1960, 1961). I have had the privilege of visiting Dr. 
Mills in his home (he is now deceased), and he showed me much of his original material, as well as leaving me a gift of some of his teaching materials. Since these original contributions of Dr. Mills, rapid rewarming in water at $40-42^{\circ} \mathrm{C}$ has been a widely accepted method for treatment of severe hypothermia (Mills et al. 1998).

\section{Accidental hypothermia}

Accidental hypothermia is defined as the unplanned reduction in core body temperature to less than $35^{\circ} \mathrm{C}$ (Turk 2010). Hypothermia then can be categorized as primary, when an otherwise healthy person who is exposed to cold conditions loses core body heat, or secondary, when a sick or disabled (injured) person is exposed to cold while lacking the usual homeostatic mechanisms to maintain normal body temperature. Hypothermia can also be categorized as acute or chronic (subacute). Acute hypothermia occurs when the affected individual becomes cold rapidly, for example by accidentally falling through thin ice and being immersed in cold water. Chronic hypothermia describes the situation where a person is debilitated, and fights for days to remain alive, often is malnourished during this period, and where they finally succumb to hypothermia. A typical example of this is a person with some dementia, who has been out picking berries during the fall season, gets lost, but can maintain themselves for a time with water from local streams and berries. But, they are unable to survive the cool temperatures after slowly losing body temperature over many hours.

In Sweden, accidental hypothermia has been thought to cause approximately 30-45 deaths per year (Albiin and Eriksson 1984), and this general incidence can be confirmed at the Swedish Central Statistics Bureau (SCB 2000). This corresponds to an annual incidence of 0.3-0.6 per 100.000 inhabitants. There has long been a suspicion amongst those that treat hypothermia that this incidence was an under-approximation, in part since some other countries with warmer climates report higher annual incidences- for example in Montana (1.58/100 000), Wyoming (1.57/100 000), and New Mexico (1.30/100 000) (CDC 2007). It is possible that individuals that have suffered a cardiovascular incident (stroke or myocardial infarction) and then were found dead outside may actually have died of hypothermia, but been classified as far as cause of death for their chronic medical illness (cardiovascular disease) and no post-mortem examination was conducted (no hypothermia event recorded). Similarly, many cases of cold water immersion, where the victim has had a life-vest, have been classified as drowning since in their final moments the victims inhaled water, where in reality the victims most likely have died of hypothermia.

Hypothermia, which leads to death, is thought to occur primarily in three groups: intoxicated individuals (most often ethanol) (Hirvonen and Huttunen 1976; Albiin and Eriksson 1984), individuals with psychiatric illness and dementia, and finally individuals with activities outdoors where they suffer an injury which means that they cannot extricate themselves from their situation. In this last group, 
one can include those that fall in cold water, those that get lost in uninhabited areas, and those that suffer from trauma (for example, a broken leg) where they cannot get themselves out of the situation or to shelter.

Hypothermia, with or without a fatal outcome, has been observed not uncommonly in connection with outdoor activities, including mountain touring where weather conditions deteriorate rapidly such that the individuals have difficulty finding adequate shelter. The Anaris accident in 1978 was a tragic example of this. Another example of this occurred in 1986 on Mount Hood in Oregon, USA, where 11 youths were on the mountain as part of a school trip when they were surprised by sudden bad weather (Wilkerson and Hamlet 1986). They took shelter in a snow-cave, though 9/11 did not survive. On Mount Everest, in 1996, 9 seasoned mountain climbers (from four different simultaneous expeditions/teams) died of hypothermia during a storm. Contributing factors included exhaustion, strong winds, hypoxia, inadequate experience, and bad judgment (Krakauer 1998).

Hypothermia occurs in connection with accidents in cold climate in sparsely populated areas, and in winter this is probably more common than is currently recognized. Severe injuries (multiple trauma) leads to degradation of the body's ability to maintain temperature homeostasis, leading to an injured person's inability to resist cooling, particularly when the ambient temperature is very low. The combination of trauma and hypothermia also lead to impaired coagulation making the outcome worse than in victims without hypothermia (Jurkovich 1987).

\section{Predisposing factors}

In theory, there are two general processes that lead to hypothermia: first, a predisposition or general condition, such as injury or illness, and second heat loss in relation to environmental factors. Conditions that predispose for cold injuries include those that lead to reduction in thermal energy production, increased body heat loss, or impaired thermoregulation. Advanced age, with corresponding reduced muscle mass and aged neuromuscular coordination, leads to a decreased capacity to shiver (Young 1991) often combined with less ability to increase metabolic rate in proportion to the metabolic demands in cold exposure (Goldman et al 1977; MacLean and Emeslie-Smith 1977; Reuler 1978; Schrijver and van der Maten 1996). Both of these factors can contribute to reduced heat production in elderly victims of hypothermia. Elderly individuals often also have a reduced fatty layer under their skin, which means a reduced temperature insulating effect due to this missing fatty layer, as well as a reduced resource of fatty tissue for oxidation (heat production). Newborns, immediately after birth, have a reduced capacity for heat production, but already after a few hours they adapt to their new environment as far as temperature regulation. Within 5 days, they have dramatically increased their lipolytic activity, and are able to oxidize lipids in brown fat tissue, generating warmth (Peristein et al. 1974; Himms-Hagen 1984; Robinson and Seward 1986; Iyenger and Bakoo 1991). Some endocrine illnesses, including hypothyroidism 
and hypopituitarism, are characterized by decreased heat production, lower resting body temperature, and impaired central temperature regulation. Severe malnutrition leads to reduced fat reserves with decreased insulation properties of the thin subcutaneous layers; the metabolic reorientation for energy supplies involves catabolism, and this does not reach normal levels for heat production if the person is exposed to cold. Dermatological illnesses, such as psoriasis and many of the different forms of dermatitis, injure the skin barrier, leading to increased heat losses (Bettley 1957; Krook 1960; Reuler et al. 1977). Convective heat loss is important if the injured skin barrier is open to air. This is particularly relevant for burn injuries, where evaporation occurs from a large area of raw tissue. Evaporation causes rapid heat loss. There can also be temperature loss from a burn if initial treatment involves cooling with cold liquids or chemical products (Livingstone and Groggins 1984). Alcohol consumption leads to increased heat losses during moderate hypothermia by vasodilation in the skin. With severe cold exposure, the usual reflex peripheral vasoconstrictive responses are impaired (Johnston et al. 1996).

Injuries in the central nervous system, such as intracerebral bleeding and subdural hematoma, as well as chronic illnesses like Parkinson's disease, Alzheimer's disease or neoplasms can indirectly lead to impaired temperature regulation (Fox et al. 1970, Chang and Gill 1981). With spinal cord injuries, the afferent and efferent autonomic nerve fibers involved in thermo-sensing and thermoregulatory effector activities can be interrupted, leading to both increased heat loss and impaired heat generation (Pledger 1963; Ashworth et al. 1982; Menard and Hahn 1991). Peripheral neuropathies, such as that caused by diabetes mellitus, can impair temperature regulation capacity; high plasma osmolality related to poorly regulated diabetes mellitus, as well as hypoglycemia or ketoacidosis all have a negative effect on the thermoregulatory activity of the hypothalamus. In a similar way, uremia can negatively affect thermoregulation (Neil et al. 1986; Guerin and Meyer 1987; Johnson and Gamble 1991; Anburajan et al. 2011).

Traumatic injuries have a potent negative effect on thermoregulation. Distal to any injury, the sensory and autonomic effector nerve cell traffic can be interrupted, leading to loss of ability to generate vasoconstriction in response to cold. Blood volume loss and hypotension can negatively affect central nervous system thermoregulation.

Temperature loss and environmental factors

When a person is exposed to cold, thermoreceptors in the skin send signals to the hypothalamus, and a peripheral vasoconstrictive response is generated. Bloodflow to the skin is reduced, limiting heat energy loss through the skin. Vasoconstriction occurs first in the fingers and toes, hands and feet, and, later, the arms and legs. The peripheral circulation in the extremities is successively reduced starting distally, and then moving more proximally. The peripheral circulation to the head 
and scalp is less innervated with sympathetic fibers, and vasoconstriction in these superficial vessels does not occur to the same extent during cold exposure. The intracranial vessels do not respond to cold with vasoconstriction. This means that during cold exposure, heat loss from the head can be relatively greater than from other parts of the body. Proportionally, heat loss from the head increases as peripheral vasoconstriction in the legs and arms increases. On the other hand, cerebral blood flow and temperature are relatively preserved during initial coldinduced peripheral vasoconstriction. Heat loss from the head, in cold conditions (for instance in $-10^{\circ} \mathrm{C}$ ambient temperature) can amount to approximately $50 \%$ of total heat loss, and this relative amount of heat loss from the head can increase further as cooling continues (Froese and Burton 1957).

Heat loss from the body increases if conditions are windy and wet. Water in contact with the body dissipates body heat up to 25 times more effectively than air at the same temperature. At water temperatures of $30-32^{\circ} \mathrm{C}$, even if the body experiences this as somewhat warm, body thermo-neutrality would be threatened and thermoregulatory warming mechanisms would be activated. The critical water temperature, below which most people begin to lose body temperature, is approximately $30-32^{\circ} \mathrm{C}$. For persons with very low body fat content, this critical temperature can be closer to $35^{\circ} \mathrm{C}$, while those with quite a large fatty (insulating) layer this critical water temperature can be below $30^{\circ} \mathrm{C}$. Clothing is also important during immersion in cold water and whether or not the water surrounding the person is moving or still. Convective heat loss in moving water is just as important as in air and wind. Here again, pre-existing illness or injury (thermoregulatory function) is important in determining the likely amount of heat loss in immersion. A number of reports have examined likely or possible survival times for immersion at different water temperatures and conditions (Molnar 1946; Keatinge 1969; Hayward 1975 (a); Boutelier 1979). There is support for the idea that a human immersed in $0^{\circ} \mathrm{C}$ water for 20 minutes (still water) should survive consistently and suffer only minor core body temperature reduction, but thereafter approximately $50 \%$ of normal individuals would cool to the point that they would lose consciousness if immersed for a further 90 minutes (110 minutes total). Immersion in these conditions beyond 110 minutes is not likely to be survivable, due to hypothermia.

There have been a number of case reports which describe extreme hypothermia, heroic rescue and rewarming, and even survival (Gilbert 2000, Hughes A 2007), though none of these case reports have contradicted the findings of the non-survivability of immersion in cold water for more than 110 minutes.

The reasons for non-survivability of prolonged cooling are probably multiple. For instance, during immersion in $2^{\circ} \mathrm{C}$ water after 7 or 8 minutes the body loses neuromuscular coordination, and the victim can no longer grip anything or hold on to anything, or even swim. At this point, the risk for drowning can be real even before core body temperature has dropped significantly, if one is not wearing a floatation device or cannot be pulled out of the water. During the Titanic catas- 
trophe on April 14, 1912, since there were icebergs in the water, it can be assumed that the water temperature was approximately $0^{\circ} \mathrm{C}$. Everyone that ended up in the water when the ship sank, even those with life vests on, was found dead. The rescue ship Carpathia arrived at the scene 1 hour and 52 minutes after the Titanic sank, and most of those who were found dead were wearing life vests and their heads were above water. They had not drowned- they had died from hypothermia. This observation agrees with the survivability times for cold water immersion that are found in more modern reports (Tikuisis 1997; Tipton et al. 1999). During the Estonia catastrophe on September 28, 1994, the water temperature was $12-13^{\circ} \mathrm{C}$ (Kamedo 1977), and survival times from those rescued from the water 7 to 8 hours later agrees with that predicted by the Molnar and Hayward diagrams and Wisslers thermal model for predicted heat loss during immersion (Molnar 1946; Wissler 2003). Heat loss during immersion in cold water increases with swimming and other physical activity, such as treading water or struggling in rough water (Hayward 1975 (b)). In still water, there is a micro-layer of relatively warm water which the body warms, and which remains in contact with the skin and keeping the body warm. With physical activity or streaming water, this warm 'film' with its insulation effect is broken up, and heat loss is accelerated.

Wind increases risk for body temperature loss based on this same convective principle- the still warm air film surrounding the body is broken up by the moving air. The higher the air velocity is over the skin surface, the more convection heat loss that occurs. The body steadily loses heat energy to the cooler air next to the skin. Strong wind and cold air temperatures clearly constitute a threat to body temperature. In 1945, Paul Siple (Siple and Passel 1945; Paton 1999) described the relation between wind and air temperature as the 'wind-chill' index. The index describes the relative temperature for still air. Siple and his colleagues were researchers in Antarctica, and they placed containers of water on the roof of their barracks, and noted the wind speed, air temperature, and time needed to freeze a known amount of water. The result was a classic table showing the cooling effect of moving cold air on skin, with different wind speeds and air temperatures. For example, the combination of air at $-15^{\circ} \mathrm{C}$ and hard wind (14-20 meters/second) provide the chilling effect of still air at $-38^{\circ} \mathrm{C}$. Modern computing allows simulation and testing, which has recently confirmed the strong chilling effects of high winds (Danielsson 1996; Shitzer 2006). Since wind-chill effect is not a temperature, but instead a calculated cold factor, it is expressed without a temperature unit.

Direct contact with cold objects or cold surfaces can lead to significant heat loss. If an injured person lies down or sits on a cold surface, they will lose heat depending on the temperature differential between their body and the surface. Metal is particularly effective in transmitting away heat- it has a heat-conducting effectiveness 9000 times greater than air. Cold liquids on the skin effectively take up heat, and when they evaporate cause additional heat loss. Light hydrocarbons (gasoline, for example) evaporate very rapidly. In a cold environment hydrocarbon 
evaporation reduces local body heat so rapidly that it can lead to local cold injury on bare skin.

In H.C. Andersen's literary representation of hypothermia, the story of the Little Match Girl, the child had many of the pre-conditions for cold injury. The ambient temperature was low. She had no insulating covering for her head. No shoes. It was snowing (melting snow on her would mean that she could not keep dry). She was hungry and poorly nourished. The cold environment, poor protective clothing, degraded personal heat production, and inability to keep dry all contributed to accelerated heat loss and poor body heat production. Her feet were described as 'red and blue', and clearly strong peripheral vasoconstriction was occurring in a reflexive effort to try to conserve central body temperature, though her general physical capacity quickly deteriorated (she sat down and never was able to get up). She sat down on a surface that was likely snow-covered, and thereby accelerated her heat loss. Her physical inactivity was then a sign that she had limited capacity to generate own heat. This story was a graphic illustration of the clinical circumstances surrounding cold injury.

\section{Pathophysiology}

Exposure to cold leads to a generalized stress response involving intensive sympathetic nervous system stimulation, with increased heart rate and general vasoconstriction (centralization of blood volume) along with increased oxygen consumption and increased respiration (ventilation, seen most simply as increased respiratory rate). With decreasing body temperature, the initial cold 'stress' disappears, and a general slowing of all bodily functions occurs.

\section{Nervous system}

In the central nervous system (CNS), there is stimulation first, with cold 'stress'. From a core body temperature of $35^{\circ} \mathrm{C}$ down to $25^{\circ} \mathrm{C}$, there is a decrease in CNS metabolism of 6-10\% per degree temperature decrease (Michenfelder and Milde 1991). The EEG amplitude decreases progressively in relation to temperature drop, starting at core body temperatures around $33^{\circ} \mathrm{C}$. At $19^{\circ} \mathrm{C}$, the EEG is usually isoelectric (Ehrmantraut et al. 1957; Fitzgibbon et al. 1984). In the peripheral nervous system, there is hyperreflexia at core body temperatures between 35$32^{\circ} \mathrm{C}$. At lower temperatures there is hyporeflexia. Pupils become dilated at approximately $32^{\circ} \mathrm{C}$ core body temperature. Pupillary response to light, eye movements and general muscular stretch reflexes are all generally absent when core body temperature is below $27^{\circ} \mathrm{C}$ (Danzl et al. 1995).

Mentation during hypothermia initially involves trying to find warmth and protection, as well as food. With decreasing body temperature, the affected person's will to struggle and get out of the danger is blunted. Typically, hypothermia victims can be apathetic, reason poorly, and have impaired memory. Hypothermia victims often make poor decisions. They typically have slurred speech and an 
apathetic appearance, mixed with aggressive confusion which can appear similar to psychosis. Level of consciousness decreases with progressive decrease in core body temperature, and most victims with a temperature of $30^{\circ} \mathrm{C}$ are somnolent or obtunded. At $28-26^{\circ} \mathrm{C}$ and below, unconsciousness can be expected. There are exceptions. There are anecdotes of children, but also adults, typically alcoholics, who have been awake and talking with core body temperatures or $24^{\circ} \mathrm{C}$, though their speech was slurred (Lloyd 1973, 1996).

\section{Circulatory system}

The circulatory system during mild hypothermia shows signs of sympathetic nervous system activation and expression. The initial tachycardia begins to disappear as body temperature drops below $34^{\circ} \mathrm{C}$, and usually gives way to bradycardia. At $28^{\circ} \mathrm{C}$, approximately $50 \%$ of hypothermia victims have bradycardia (Blair 1964; Sinet et al. 1985; Jurkovich 2007). Cardiac output and blood pressure initially increases in response to mild hypothermia, but with lower temperatures there are decreases in these, typically in parallel with decreases in heart rate. Cardiac output at core body temperature $25^{\circ} \mathrm{C}$ is typically less than $50 \%$ or the individual's resting normal cardiac output, assuming continuation of a sinus rhythm. The heart's conduction system is very sensitive to decreases in body temperature, and below $32^{\circ} \mathrm{C}$ multiple dysrhythmias can occur, both during the cooling phase and during the rewarming phase (Emslie-Smith 1958; Duguid et al. 1961; Edwards et al. 1979; Clements and Hurst 1972). New onset atrial fibrillation during hypothermia is observed most often at $32^{\circ} \mathrm{C}$ and below. A $\mathrm{J}$ wave, or 'Osborne' wave on the electrocardiogram, which is a positive wave between the QRS and T waves, is common during hypothermia (found in $80 \%$ of those with temperature below $32^{\circ} \mathrm{C}$ ). The $\mathrm{J}$ wave is usually most easily observed in leads II and V6, and is not pathognomonic for hypothermia; it can also be observed in other illnesses such as sepsis or CNS injuries. At temperatures below $32^{\circ} \mathrm{C}$, ventricular extra-systoles are common, even ventricular tachycardia. At temperatures below $28^{\circ} \mathrm{C}$, ventricular fibrillation can occur spontaneously or may be triggered by simple external mechanical stimuli.

One theory about the origin of atrial fibrillation is that the cold-induced centralization of blood volume leads to atrial over-distention. Ventricular dysrhythmias can occur either due to His-Purkinje cell irritability during hypothermia or possible re-entry phenomena where different portions of the myocardium are at slightly different temperatures. All of these factors can lead to extrasystoles, ventricular tachycardia, or fibrillation as a consequence (Covino and Beavers1958; Björnstad 1991; Aslam et al 2006). Electrolyte disturbances, particularly hyperkalemia, are common in hypothermia, and also contributes to the risk for dysrhythmias. Impairment of calcium ion fluxes and restitution in myocardial cells during hypothermia has also been implicated in hypothermia-related dysrhythmias (Kondratiev 2008). 
Many hypothermia victims may finally succumb with malignant dysrhythmiasasystole or ventricular fibrillation. Some hypothermia researchers that suggest that asystole is the most common rhythm, and that ventricular fibrillation is usually iatrogenic, or triggered by events related to rescue or treatment (Southwick and Dalglish 1980; Bangs 1984; Ferguson 1985). Hypovolemia, hypoxemia, and mechanical stimulation are all possible triggers for ventricular fibrillation. It is thought that physically rough handling, for example during rescue, is a potential threat for triggering dysrhythmia, particularly when core body temperature is below $28^{\circ} \mathrm{C}$ there are a number of reported anecdotes of hypothermia victims who were awake and talking, but suffered ventricular fibrillation when being lifted over to a stretcher or moved into a vehicle (helicopter). In transit to hospital or in hospital, precordial stimulation (chest compressions!), central vein catheterization have been linked anecdotally to initiation of ventricular fibrillation, often in the presence of acid-base disturbances and coronary vasoconstriction that is found with severe hypothermia (Swan et al. 1953; Vandam and Burnap 1959; Westin et al.1961; Mouritzen and Anderson 1965; Lloyd and Mitchell 1974; Swain et al. 1984). However, when assessing the ability to survive a cardiac arrest in hypothermia one should consider that the time for irreversible cerebral damage after cardiac arrest will be considerably prolonged due to the decreased cerebral metabolism, compared to normal core temperature; at $30^{\circ} \mathrm{C} 6 \mathrm{~min}$, at $25^{\circ} \mathrm{C} 10 \mathrm{~min}$, at $20^{\circ} \mathrm{C} 18 \mathrm{~min}$, at $15^{\circ} \mathrm{C} 30 \mathrm{~min}$ and at $10^{\circ} \mathrm{C} 60$ minutes (Steinman 1986).

The man, who capsized his canoe and ended up severely hypothermic, but still alive, had a core temperature low enough to make his heart extremely vulnerable to mechanical stimuli. While he was being carried out he developed ventricular fibrillation. It is widely recognized that many arrhythmias occur at body temperatures below $28^{\circ} \mathrm{C}$ and the risk for this is high. Knowledge and understanding of the pathophysiology in severe hypothermia among rescue workers in the field helps save lives.

Peripheral vasoconstriction is part of the body's initial resistance to temperature reduction, and can lead to significant redistribution of blood. Half of the blood volume in the skin (the body's largest organ) can be shunted to the central blood volume. The resulting increase in blood pressure and renal blood flow leads to diuresis ('cold diuresis') as well as interstitial edema.

\section{Paradoxical undressing}

Vasodilation, or profound vasoplegia, occurs as the peripheral nervous system loses its capacity to respond to autonomic nervous system signalling. This may lead to pre-terminal vasodilatation. A hypothermia victim may disrobe (paradoxical undressing), and the mechanisms are unclear, though it may be in response to a feeling of warmth, despite being in a very cold environment. It has been repeatedly observed that some fatal hypothermia victims have taken of their shirts, their pants, shoes, and then walked some distance before stopping and succumbing (Wedin et 
al. 1979; Mizukami 1999). In a previous era, it was thought that this disrobing was possibly due to a criminal sexual assault. With more observations, it became clear that this is associated with hypothermia. The mechanism, incidence and associated factors for paradoxical undressing are not well understood, and the pre-mortal circulatory events in severe hypothermia victims when this behaviour occurs obviously cannot be studied prospectively.

\begin{abstract}
'After-drop'
During the rewarming of moderate or severe hypothermia, a victim's core body temperature may continue to decrease despite moving the victim to warm surroundings and despite active rewarming. There are two widely discussed possible explanations for this. The first is that 'afterdrop' represents the physical/kinetic distribution of heat energy along simple physical gradients between the cold exterior layers of the body and a warmer core. A second theory holds that relaxation of intense vasoconstriction in cooler and extremities/body wall/skin leads to peripheral dilatation that 'steals' heat from warmer central blood (Davies et al. 1967; Webb 1973; Hayward and Steinman 1975; Golden and Hervey 1977; Reuler 1978; Harnett et al. 1980, 1983( a), ( b); Steiman 1987; Giesbrecht and Bristow 1992). There is probably a contribution from both of these processes. In clinical practice, it is important to recognize this phenomenon, and consideration of this (avoiding further cooling of the heart, if it is already below $30^{\circ} \mathrm{C}$ ) might influence choice of a rewarming method.
\end{abstract}

\title{
Respiratory system
}

The respiratory system is involved in the cold 'stress' period, with more minute ventilation often manifest as a higher respiratory rate and tidal volume, though with progressive cooling, ventilation decreases. When there is a sudden cold water immersion, a strong 'gasp' reflex is activated followed by hyperventilation typically leading to a respiratory alkalosis. This can be so profound that decreased consciousness and even an epileptic seizure can occur, which is very dangerous when in the water, incurring risk for aspiration of water and drowning. There can also be strong autonomic nerve system stimulation of the diving reflex at the same time, which can result in a malignant dysrhythmia (Shattock and Tipton 2012). The initial increase in respiratory drive with mild hypothermia disappears, and at core body temperatures $33^{\circ} \mathrm{C}$ and below, respiratory drive is depressed, and decreased respiratory minute ventilation follows. At temperatures below $29^{\circ} \mathrm{C}$ the respiratory center in the brainstem no longer responds to carbon dioxide retention, and respiratory acidosis ensues. At the same time, during cooling, there is a temperature-dependent reduction in elasticity of the thoracic body wall, and the respiratory musculature no longer can easily and effectively inflate the lungs/expand the ribcage, also contributing to respiratory insufficiency during moderate and severe hypothermia (Okada and Nishimura 1990). 
Renal function and fluid balance

Renal function and fluid balance are affected by hypothermia. Peripheral vasoconstriction and centralization of blood volume during early hypothermia produces a 'cold diuresis'. At one time, it was thought that anti-diuretic hormone (vasopressin) release was stimulated by hypothermia, though this was disproven when it became clear (Lennquist 1971; Lennquist 1972, Lamke et al. 1972; Lennquist 1974) that this diuresis involved significant loss of both salt and water. At the same time, plasma moves to the extravascular compartment, leading to progressive hemoconcentration. After a significant 'cold diuresis', and during rewarming, these fluid shifts and hemoconcentration reduce total blood volume. When relaxation of the intense peripheral vasoconstriction relaxes, blood pressure falls. If in the active rewarming phase, relaxation of peripheral vasoconstriction occurs very rapidly, then hypovolemic shock ('rewarming shock') can result. A hypothermia victim can also have suffered from an injury and bleeding, leading up to their hypothermic condition. Fluid resuscitation may also be necessary if the victim has been injured and lost blood, or has lost fluid and electrolytes during severe prehypothermia exertion and sweating.

\section{Hemostasis and coagulation}

Hemostasis and coagulation are impaired during hypothermia. Many coagulation enzymes do not work effectively at lower temperatures (Ferarra et al. 1990; Reed et al.1990, 1992). Platelets can be sequestered in the liver and spleen during hypothermia, and bone marrow depression at lower temperatures can lead to less platelet availability (O'Brien et al. 1982; Pina-Cabral et al. 1985; Rosenkrantz 1985). Platelet counts and platelet function can decrease in hypothermia to levels that usually are associated with spontaneous bleeding (Kattlove and Alexander 1971; Kattlove and Alexander 1972; Shenaq et al. 1986; Valeri et al. 1987; Patt et al. 1988). Between $36-33^{\circ} \mathrm{C}$, impaired platelet adhesion and poor hemostasis is prominent, while at lower temperatures (below $33^{\circ} \mathrm{C}$ ), impaired coagulation enzyme activity also is present, resulting in an impairment of both hemostasis and coagulation. At a core temperature of $33^{\circ} \mathrm{C}$, there is an approximately $50 \%$ reduction in clotting capacity compared to normal.

With this pathophysiology in mind, one can speculate that the child in the 'Little Match Girl' story probably succumbed to asystole or ventricular fibrillation. She hallucinated in the story, indicating clear CNS effects of hypothermia, which might even have resembled psychosis. She possible could have experienced a paradoxical warm feeling for a short period, though not described in the story.

When a severe hypothermia victim is found and they are unresponsive, there is always a question whether they are actually dead or instead unconscious with a very low heart rate and minimal respiration. In severe hypothermia, with no recognizable pulse and unresponsive dilated pupils, these two conditions can be difficult to distinguish. It is possible that she was still alive, though with slow 
bradycardia which at some point degenerated to ventricular fibrillation and then asystole when she was taken care of. Even if they had discovered that she was still alive, though severely hypothermic, it is most likely that there was nothing they could have done to save her.

\section{The clinical manifestation}

During exposure to cold, and before cooling of core body temperature, there is a period where a potential hypothermia victim will/should consciously try to find shelter and protection from the cold, and where hypothermia can be recognized by appearance and behavior. Early clinical manifestations include hunger, nausea, fatigue, aggressiveness, impaired motor coordination, ataxia, apathy, and confusion. With further decreases in core body temperature, the victim becomes anxious and neurotic or displays unpredictable behaviour, and ultimately hallucinates. As core body temperature decreases successively to around $30^{\circ} \mathrm{C}$, mentation slows significantly, and at $28-26^{\circ} \mathrm{C}$, most victims become unconscious.

Initially the skin is pale and vasoconstricted. Muscle tone increases with shivering, which can start with a reduction in body temperature as small as $0.5^{\circ} \mathrm{C}$, and increase body heat production 2-5 times the usual resting amount. Shivering becomes maximal at approximately $35^{\circ} \mathrm{C}$. As shivering slows and stops, body temperature falls. Shivering stops somewhere between 33 and $30^{\circ} \mathrm{C}$ for most individuals, partly because of depletion of muscle glycogen and as a direct result of cooling of the muscle cells and slowed neuromuscular function. Muscle rigidity develops with severe hypothermia. Initial hyperreflexia converts to hypo- or areflexia. The pupils dilate and become unresponsive as hypothermia progresses.

The assessment of cardio-vascular status can be confusing in severe hypothermia. The heart may be beating slowly but peripheral pulses are impalpable. Blood pressure can be difficult to measure by any means. The usual Korotkoff sounds may not be present. Heart sounds may be very dampened. Breathing can be very sporadic and superficial, and difficult to recognize.

Based on pathophysiological and clinical patterns, there has been a consensus to classify hypothermia into 3 categories: mild $\left(35-32^{\circ} \mathrm{C}\right)$, moderate $\left(31.9-29^{\circ} \mathrm{C}\right)$, and severe (28.9 and below) (Kempainen 2004). These temperature ranges are arbitrary, and they do not predict clinical manifestations with precision in individual cases. What is clearer is the progression in pathophysiological changes and deterioration in function with progressive hypothermia. In mild hypothermia, thermoregulatory (homeostatic) mechanisms should be fully operational if the victim is healthy, but, by definition, heat loss is exceeding heat production. In moderate hypothermia, the effectiveness of the patient's heat generation declines and eventually fails. More severe vital organ dysfunction ensues. In severe hypothermia, self-generating mechanisms for heat preservation and production do not function at all. Vital organ dysfunction worsens. Hypothermia and trauma in combination aggravates the pathophysiological changes that occur and the associated morbidity 
and mortality rate. The definition of mild, moderate and severe hypothermia in association with trauma need a special classification if used for prognosis; mild hypothermia $36-34^{\circ} \mathrm{C}$, moderate hypothermia $34-32^{\circ} \mathrm{C}$ and sever $<32^{\circ} \mathrm{C}$ (Jurkovich 2007).

\section{Laboratory findings}

There are some important laboratory changes associated with hypothermia. Hematocrit and haemoglobin rise as a result of cold diuresis and extravasation of fluids to the interstitial space. Leukocyte and platelet counts decline due to bone marrow depression and sequestration in the liver and spleen (Blair et al. 1964; Lewin et al. 1981; Shenaq et al. 1986; O'Brian et al 1982; Pina-Cabral 1985; Rosenkrantz 1985). Acid-base balance changes are to be expected, with an initial respiratory alkalosis due to hyperventilation followed by a progressive respiratory and metabolic acidosis. Inside cells, however, there can be a relative alkalosis, promoting the efficiency of the transmembrane transport of electrolytes (Rhan 1974; Rahn et al. 1975; Ream et al. 1982; Baraka 1984; Baraka et al. 1992). Interpretation of blood gases, when the core body temperature is low, has been a subject of controversy. There have been two traditions, at least in the community of hypothermia and cardiopulmonary bypass; in the $\mathrm{pH}$-stat system, blood gas values are corrected to the actual core temperature. In the alpha-stat tradition, blood gases are interpreted without consideration of body temperature (Murkin 2007). Many practitioners have chosen to carefully and cautiously treat the acidosis $(\mathrm{pH}$ under 7.20) in the context of accidental hypothermia and cardiac arrest, particulary with hyperkalemia. Though there is little scientific evidence to support this, it conforms to the current Acute Life Support guidelines (Deakin et al. 2010).

Electrolytes changes are common in moderate or severe hypothermia: potassium can be high or low. It is not necessarily so that potassium usually high in acute hypothermia, and in chronic (sub-acute) hypothermia (Astrup et al. 1981; Koht et al. 1983; O'Connor 1986; Boelhouwder et al. 1987). Serum potassium levels can be extremely low or high, and change during rewarming. Therefore, potassium should be assessed frequently, and be treated aggressively when out of balance, in order to reduce the risk of dysrythmias from hypothermia alone. Serum creatinine and urea are often high, since hypothermic kidneys are not able to secrete waste products as effectively as usual. Blood glucose is usually high in the cold stress phase, but low during/after shivering, which results from exhaustion of glycogen stores. Amylase levels may be high, and may indicate pancreatitis (Mac Lean et al. 1973, 1974; White 1982).

\section{Treatment}

The first treatment is delivered in the field. It is important to quickly recognize the degree of hypothermia, and this can be done based on degree of consciousness, presence or absence of shivering, signs of breathing or pulse, and core temperature 
(Durrer et al. 2003). It should be recognized that severe hypothermia can mimic death, and that it is impossible to be sure that death has occurred unless there are other obviously lethal injuries (Edwards et al. 1970; Gregory et al. 1972; Auerbach 1990). Every reasonable effort must be made to get a hypothermia victim to a hospital where full diagnostic and resuscitation resources are available.

The first person to the accident site for a hypothermia victim can themselves be subject to harsh weather conditions or dangerous terrain. On the other hand, hypothermia can even occur indoors, so there is a broad spectrum for victim circumstances. Regardless of these, basic resuscitation procedures should be followed when initiating care of a hypothermia victim. These include securing a free airway, immobilizing the cervical spine, assuring ventilation and oxygen delivery to the lungs, confirming/supporting circulatory activity, and then checking for other major injuries.

\section{Environmental control}

Once this quick survey is finished, then concern for exposure and environmental control becomes important. With ongoing resuscitation activities, the rescuers must still think about stopping heat loss, and rewarming. The should insulate the victim with dry blankets, rescue bags or dry clothing, number of layers depending on the environmental temperature, wind speed and moisture. An outer wind-tight and moisture-proof shell will enable the ensemble to maintain the insulating capacity better and for a longer time interval (Henriksson et al. 2009). The addition of active warming devices, such as a charcoal heater, chemical heat pads, or warm water-bags to the torso, will improve the thermal comfort and may help prevent further heat loss (Lundgren et al. 2009; Lundgren et al. 2011). Caution is advised when applying heat sources to a cold patient; heat sources should not to be warmer than $43^{\circ} \mathrm{C}$ when applied directly to the skin, in order to avoid the burn injuries (Henriques and Moritz 1947).

\section{Airway and breathing}

Concerning the airway and breathing, it is recommended to intubate the trachea if the airway is not clearly free, and to give supplemental oxygen (40-60\%). Nasal intubation attempts have been shown in hypothermia victims to be associated with significant bleeding. Noncompliant lungs and ribcage in the hypothermia victim must be taken into consideration when trying to achieve normoventilation (Lloyd 1996). There has been a debate to whether or not tracheal intubation attempts will trigger VF, but the risk is minimal (Danzl et al. 1987), and adequate oxygenation of the patient and protecting the lungs from aspiration should be the primary concern.

\section{Circulation}

When checking for pulses, one must use a warm hand, and then check for at least a minute before one can say that they have not found a pulse, and even then 
sensing a pulse that is present in a hypothermia victim can be difficult. A hypothermia victim should be given a sugar-containing drink early (if awake and cooperative) or sugar-containing intravenous fluids. Intravenous infusions should be warmed (if the victim is not awake) and kept warm throughout the infusion. Establishing intravenous access in a hypothermia victim can be difficult, and an early decision to proceed with an intraosseous cannula is recommended, remembering that any delay in getting a hypothermia victim to hospital contributes to morbidity and mortality (Fowler et al. 2007).

Chest compressions should be started if there are no detectable pulses, or no ECG complexes if a monitor is available, as long as there is reason to believe that the cardiac arrest occurred within the last two hours, or if there is an observed cardiac arrest. Cardiopulmonary resuscitation with external cardiac massage can be life-saving in hypothermic patients with cardiac arrest. However, cardiac arrest can be difficult to diagnose in hypothermia. The heart may be functionally beating even if not detectable and mechanical stimuli to the chest wall can likely trigger ventricular fibrillation. Therefore, chest compressions must not be started until cardiac arrest has been confirmed. This is a difficult diagnostic step for rescuers in the field, unless an ECG monitor is available. The same ventilation and chest compression rates should be used as for a normothermic patient, though there has been debate concerning the optimal rate for chest compression when a victim is severely hypothermic. Chest compressions should not cause delay other measures including tracheal intubation and central venous cannulation when indicated (Soar et al. 2010).

If ventricular tachycardia or ventricular fibrillation is detected, then defibrillation should be performed with maximal energy. If the dysrhythmia persist after 3 attempts defibrillate/cardiovert, then further shocks should be delayed until the victim is rewarmed to at least $30^{\circ} \mathrm{C}$. It is also recommended to not administer adrenaline or other resuscitation drugs until a hypothermia victim is at least $30^{\circ} \mathrm{C}$. At that temperature, it is recommended that the interval between drug doses should be doubled (Soar et al. 2010). The pharmacodynamics for resuscitation drugs for patients at $30^{\circ} \mathrm{C}$ is not well understood which is one of many clinical dilemmas in hypothermia treatment where there is scant study or evidence concerning pharmacological aspects of severe hypothermia. In general though, it is thought that at that temperature, there is stronger protein binding, slower metabolism of drugs, and diminished effect and repeated drug doses in hypothermic conditions may lead to toxicity after rewarming (Lloyd 1996; Soar et al. 2010). After reaching $35^{\circ} \mathrm{C}$, standard resuscitation protocols can be used again.

\section{Measuring temperature}

Measuring temperature for hypothermia victims in the prehospital setting is a challenge. Weather conditions can be difficult and so can finding a low reading thermometer reliable in that specific environment be, but measuring the tempera- 
ture should be prioritized. The interpretation of vital parameters is temperature dependent; core temperature is a decisive factor for the sensitivity to mechanical stimuli and the degree of coagulopathy. Treatment in the field, the choice of receiving hospital (an issue for the transport process) and finally the choice of rewarming methods are all guided by body temperature. Potential and available sites for measuring temperature in the field setting are the ear, mouth, axilla, rectum and in some situations the esophagus and the urinary bladder. Temperature in the esophagus correlates best with true core temperature defined as pulmonary artery temperature (Fulbrook $1993 \mathrm{a}, \mathrm{b}$ ). Good correlation with core temperature is also described from rectum, the urinary bladder and membrane tympani (Moran and Mendal 2002; Fallis 2002; Lefrant et al. 2003). In the field, is difficult to pass esophageal probes due to the gag reflex and the need for a monitor. Rectal temperature measurement also can be difficult to implement due to clothing. In order to be accurate, a rectal probe needs to be placed with the tip $10 \mathrm{~cm}$ into the rectum. Bladder thermometers are accurate but also difficult to use in the field. However, a temperature probe in a Foley catheter or an esophageal probe should be considered in the ambulance/transport setting. Temperature measurement directly to the eardrum is painful, but useful because the temperature correlates well with pulmonary artery temperature. Infrared emission detection thermometers are inaccurate in cold environment and for low core temperatures reading (Oberhammer et al. 2008; Radwin et al. 2009). The Metraux thermometer for closed ear canal temperature is accurate and appropriate in a wide range of ambient temperatures, and this may be a good alternative for measurements in the field of a hypothermic patient (Walpoth 1994).

Oral temperature is dependent on whether the mouth is open or not, and in an unconscious patient with open mouth the oral temperature will not be accurate. In a conscious patient with a closed mouth, it may be accurate enough for a preliminary assessment, but also may be deceptively low. Temperatures in the axilla do not reflect a true core temperature, rather the temperature of the skin which is falsely too low.

Because of the importance of identifying a core temperature, and problems and patient risks (unnecessary treatment, incorrect use of expensive and limited resources) related to measuring a falsely low temperature, measuring and recording a core temperature in the field is very important. Both the measurement methods and the sites need to be recorded in order for others that are later involved in the health care system to be able to critically assess the first steps and treatment decisions.

This preceding section describes the very demanding routine for the care of hypothermia victims in the prehospital setting, and part of the survey in my first Paper in the thesis was designed to confirm the strengths and identify the weaknesses in this practice in our region. Hospital practice also seems to have quite a bit of variability in treating hypothermia victims, though through high ambition 
levels, education and practice review, we hope that there is significant progress in care and patient safety over time.

\section{Rewarming strategies}

Rewarming can be either active or passive, and if active either external or internal. When choosing a rewarming technique core temperature, level of consciousness, respiratory and circulatory statuses are decisive factors. In patients with a core temperature $>32^{\circ} \mathrm{C}$ who are conscious with stable respiratory and circulatory status, the choice for rewarming can be either passive or active, while for patients with core temperatures below $32^{\circ} \mathrm{C}$ rewarming should be active.

\section{Passive rewarming}

Passive rewarming includes drying and insulating the patient in a warm surrounding, with room temperature $25^{\circ} \mathrm{C}$, and administration of warm drinks with glucose. This method may be the only choice available in a field rewarming situation or when bad weather forces a rescue group to wait for a time in simple shelter in the wilderness.

\section{Active rewarming}

Active rewarming can be administered either externally or internally. External procedures include a warm water bath with $40-42^{\circ} \mathrm{C}$ water (Hoskin et al. 1986). This method may have several difficulties. First, access to a bath-tub big enough may be difficult. Second, monitoring and the need for defibrillation in the water is difficult or impossible as the necessary medical technical devices are not certified for use in a wet environment. The Vangaard technique (Vanggaard et al. 1979) with a sitting patient with the extremities up to the knees and elbows in warm water is another option, and this allows superficial veins to act as heat exchangers. Both warm water techniques are effective, and either can be chosen for conscious patients, but both have practical limitations. Forced air warming with a Bair Hugger is a simple, atraumatic, and reliable method which has changed the rewarming strategy in most ICU's all over the world (Brauer et al. 1999; Kornberger 1999; Deakin 2000; Roggla et al. 2002). Used in combination with warmed intravenous fluids, this is effective even in severe hypothermia as long as the circulation is stable enough to perfuse vital organs. Forced air warming ensures good access to the patient for monitoring and other procedures if needed.

Internal methods include several options: warmed humidified air, gastric, peritoneal, bladder or pleural lavage and extracorporeal circulation (Weinberg et al. 1990; Reuler and Parker 1978; Zell and Kurtz 1985; Althaus et al. 1982; Walpoth et al. 1997). Extracorporeal techniques include hemodialysis, atrio-venous (CAVR) or veno-venous circuits (CVVHD), ECMO (extra corporeal membrane oxygenation) and cardiopulmonary bypass (Gentilello et al. 1992; Alfonzo et al. 2008; Walpoth et al. 1997; Ruttman et al. 2007). Rewarming rates for the internal 
lavage techniques are up to $1-4^{\circ} \mathrm{C}$ per hour, while the fastest extracorporeal rewarming technique with cardiopulmonary by pass warms at a rate of $1-2^{\circ} \mathrm{C}$ per 5 minutes. Choosing between the lavage- and the extracorporeal methods depends on the experience of the physician, the hospital and its equipment, and the nature of the patient. In smaller hospitals, extracorporeal techniques may not be available, leading to a decision of either transport to a larger hospital or using a lavage technique that is feasible locally. Choice of level of care, including for a possible transport system, depends on the patients needs. If the circulatory and respiratory systems are stable, a lavage technique can be used. If there is cardio-respiratory instability or cardiac arrest, the choice should be an extracorporeal rewarming procedure. During rewarming, regardless of method, close monitoring is essential. Vasodilation will expand the intravascular space with risk for hypovolemia, arrhythmias of all kinds may occur, acid-base and electrolyte balance can change quickly and need to be corrected.

\section{Prognosis}

Mortality rates for all categories accidental hypothermia has been reported to range from 20-70\% (Danzl et a. 1987; Fox et al. 1971; Goldman et al. 1977). Hypothermia, in combination with severe trauma, injury severity score $>25$, is associated with significantly higher mortality rate ranging from $40 \%<34^{\circ} \mathrm{C}, 69 \%$ $<33^{\circ} \mathrm{C}$ and $100 \%<32^{\circ} \mathrm{C}$ (Jurkovich et al 1987). Nevertheless, there are reports on survival with good quality of life for adults down to $13.7^{\circ} \mathrm{C}$ (Gilbert et al. 2000), which happened to involve a Swedish victim.

Concerning prognosis in the case of the Little Match Girl, given the ambient temperature, her state of chronic malnourishment, her impaired vital function as her core temperature decreased, this represents a severe and life-threatening state of accidental hypothermia. She may have had a chance of survival if found and treated according to today's state of the art. At that time, in 1846, her chances of survival were minimal even if found alive. In fact, she may have been alive when discovered, though that may not have been recognized. Even today, accidental hypothermia continues to be a danger, always potentially fatal in more severe cases.

\section{Frostbite}

To introduce frostbite, I provide another anecdote from my region. On January 21 1955, Evert Stenmark who was a hunter in Northern Lapland went out on skis to check his trapline. The ambient temperature was $-30^{\circ} \mathrm{C}$, with no wind. The distance to the cabin and the area for his trap line, where he planned to stay for 3 or 4 days, was 30 kilometers. The morning he arrived at his cabin, the weather had changed, and the temperature was only minus $7^{\circ} \mathrm{C}$. He found four grouse trapped in the first 7 snares, and had just put them in his rucksack when he was hit by an avalanche. He found himself buried under the snow not able to move his legs. He 
had an airpocket in front of his face. With great effort he was able to move his arms, and found a birch branch, thick as a finger, and put it through the snow up in the air, in order to obtain fresh air. Contemplating his situation, he realised that no one would look for him for days. If and when they did arrive, they might have difficulty finding him. After much effort, he was able to attach to the twig two red cinema tickets (which he had in his pocket) and the cap from a ski wax container. Six days later, his brother and a rescue team started to search for him. For two days they found nothing- no tracks, no signs of Evert. On the $8^{\text {th }}$ day after the avalanche, his brother saw something red in the snow, and when examining closer he found it to be a red paper and a cap from ski wax. He understood that Evert was there, buried under the snow. The rescue team didn't expect to find him alive, but to their surprise they found him, conscious but weak and cold, frozen stiff up to his waist. A doctor was flown in by helicopter; and Evert was treated in a nearby cabin, where they started to rewarm Evert's legs and feet with warm water. After a while, however, Evert had excruciating pain and they had to cool his legs again. After several cycles of warming and cooling they eventually had thawed his legs, though his toes were all black. At that point he was transported to the nearest health care facility, and then to the regional hospital. After six months in hospital, and after amputation of both feet, he finally returned home.

\section{Presentation and staging}

Frostbite injury is classified as either superficial or deep. Superficial frostbite has no tissue loss, and deep frostbite has loss of tissue. The initial phase of the superficial freezing cold injury presents with symptoms of burning pain soon followed by numbness and sensory loss, and with the only sign that the skin turns white. Superficial frostbite can be further classified into first or second degree, where first degree injury is characterized by partial skin freezing, erythema, but with no blisters, while second degree has full thickness skin freezing, erythema, edema and clear blisters rich in thromboxane and prostaglandins. Deep frostbite is classified into third and fourth degrees, where third degree injury involves full thickness skin- and subcutaneous freezing, hemorrhagic blisters, skin necrosis and bluish-grey discoloration follows. Fourth degree injury extends into subcutaneous tissue, tendons, muscle, cartilage and bone (Mills 1964; Ikäheimo and Hassi 2011).

\section{Predisposing factors or activities}

Risk assessment in cold injuries should include knowledge of predisposing factors or activities, individual susceptibility and situation. In several studies (Boswick 1979; Urschel et al. 1990; Hassi and Mäkinen 2000; Mäkinen et al. 2009; Ikäheimo et al. 2011; Grieve et al. 2010), the most well-known predisposing factors described are alcohol consumption, psychiatric illness or dementia, vehicular failure, and drug misuse. The occurrence of frostbite is also higher in occupational groups such as farmers, reindeer herders, and fishery workers (Hassi and Mäkinen 
2000). Cold exposure during outdoor leisure activities, like skiing, skating and especially high altitude climbing, are associated with risk of frostbite.

Individual factors

Individual factors include associated diseases such as cardiac insufficiency, angina pectoris, diabetes, depression and Raynaud's phenomenon. Smoking does not seem to increase the risk of frostbite, even though smokers have impaired microcirculation (Mäkinen et al. 2009). Chronic exposure to cold in indigenous groups, including for Arctic Indians and Eskimos, have been thought to have increased skin blood flow (Meehan 1954, 1955). It is also established the Inuits and Laps in general have higher mean finger temperature and cold-induced vasodilation responses than a control population from warmer climate zones (Brown et al. 1963; Krog et al. 1960; Miller and Irving 1962). It is not clear whether these differences are inherited or acquired. One study (Mathew et al. 1979) examined the vasodilatation response to hand immersion in $4^{\circ} \mathrm{C}$ water in indigenous American groups living in four different climate and altitude zones. He found that those living at high altitude had significantly higher heat output than those living in the south at low altitude. The findings might favour adaptation rather than genetics.

Responses to cold include a rapid and pronounced vasoconstriction, which is mediated via the sympathetic nervous system. Prolonged cooling and vasoconstriction is however often followed by cyclic, cold induced vasodilation (CIVD), "hunting response", first described by Lewis (Lewis 1930). The phenomenon is described in fingers, toes and face (Greenfield et al. 1958; Bergersen et al. 1999). A possible mechanism for the CIVD is a relaxation of arterio-venous anastomoses leading to an increase in local blood flow. The CIVD response can allow for continued use of the hands and feet in cold, even after hypothermia has begun. With time and progressive cooling, the peripheral vasoconstriction becomes fixed, and the temperature in the extremity drops fast, leading to risk of local cold injury. CIVD is commonly not observed in patients with Raynaud's "white fingers", a syndrome or disease characterized by extreme vasospasm and ischemia in the fingers triggered by cold or emotional stress.

\section{Frostbite and situation}

Situations, places and weather conditions, associated with cold injury include cold, wind, moisture or combinations of these and often simultaneous touching, lying or sitting on cold surfaces. Prolonged exposure, especially in combination with poor clothing and forced physical inactivity is a threat for cold injury. Exposure to cold in high altitude scenarios increases the risk for frostbite even more (Hashmi et al. 1998). Direct contact with cold objects or cold surfaces particularly metal, is effective in transmitting away heat. Some metals conduct heat up to 9000 times more efficiently than air. For example, fingertip temperature when touching aluminium at $-5^{\circ} \mathrm{C}$ falls in a few seconds nearly to freezing point. Cold liquids 
with a freezing point below zero Celsius on the skin effectively conduct heat away concomitantly as they evaporate. Light hydrocarbons (gasoline, for example) evaporate very rapidly, and in a cold environment hydrocarbon evaporation from bare skin captures so much local body heat that it can even lead to local cold injury.

\section{Pathophysiology}

\section{Natural history}

The natural history of frostbite includes a series of changes divided into prefreeze phase, freeze-thaw phases, vascular-stasis phase, and progressive or late ischemic phase (Mills 2002). The pre-freeze phase starts when the skin temperature falls below $10^{\circ} \mathrm{C}$ and coincides with a considerable peripheral vasoconstriction and a decrease in blood flow within the affected tissue. In this phase, vascular contents become more viscous; there is microvascular constriction and leakage of plasma into the interstitial space. With further fall in skin temperature to $0^{\circ} \mathrm{C}$ and below in the freeze-thaw-phase, ice crystals form in the extracellular space with a concomitant rise in extracellular osmotic pressure. Due to high extracellular osmotic pressure, free water is drained from the cells leading to intracellular dehydration and hyperosmolality causing trans-membrane shift of electrolytes, $\mathrm{pH}$ changes, destruction of enzymes, cell membrane lysis, and cell death. Simultaneously, during the thawing when there is vascular-stasis, microvascular function is compromised and endothelial cells are damaged, with leakage of fluids and blood from vessels. In the progressive or late ischemic phase, tissue ischemia and infarction occur due to inflammatory changes, and micro-thrombosis (Ikäheimo and Hassi 2011). Recovery from frostbite involves in part a reperfusion injury involving oxygen-free radicals, neutrophil activation and inflammatory changes. Prothrombotic and vasoconstrictive prostaglandins F2a (PGF2a) and tromboxane A2 (TXA2) have been found in high concentrations in cold injury blister fluid (Robson and Heggers 1981).

\section{Vasoconstriction}

When the skin is exposed to cold, immediate reflex mechanisms in the autonomic nervous system are activated to defend normal temperature by shivering, vasoconstriction and increased thermogenesis. The peripheral vasoconstriction described earlier is activated and controlled on several different levels: by direct effect of cold on the blood vessels and by local spinal cord reflexes. The regulation of the intensity is controlled by the hypothalamus. The impact of the local reflex control is weak in comparison to the regulatory effect from the hypothalamus. The vasoconstriction in cold exposure is mainly driven by sympathetic nervous system expression, while the mechanism of CIVD mechanism still is to be identified. One possible mechanism is that there may be a local paralysis of vasoconstrictor tone (Daanen 2003), and another is that there can be a central component caused by 
sympathetic vasoconstrictor withdrawal (Flouris and Cheung 2010; Flouris et al. 2008). For the microcirulation in hypothermia, complex mechanisms involving the autonomic nervous system and local effectors play an important role.

Autonomic nervous system expression and cold injury

The autonomic nervous system is absolutely central for our survival in challenging environments. It ensures that we maintain our vital functions without any conscious effort. While the autonomic nervous system is active in regulation of many body functions, it responds quickly to physical challenges for our cardiorespiratory system, such as changes in position or condition that might affect the circulation. The complex and multiple reflexes work to ensure substrate delivery to vital organs. The autonomic nervous system responses to cold exposure aim to preserve an adequate central circulation involving vital organs, and this means in some settings closing down peripheral circulation.

Assessing the authonomic nervous system in health and in disease or injury is challenging. One way to assess autonomic nervous system responses in cold is by analysing heart rate variability (HRV). The variation in the interval between heart beats is one of the best markers for either increased sympathetic or reduced vagal (parasymphatetic) nervous activity. The analysis of HRV normally shows three different spectral components: very low frequency (VLF) within the region 0-0.04 $\mathrm{Hz}$; low frequency (LF) component in the region $0.04-0.15 \mathrm{~Hz}$; and high frequency (HF) component in the region $0.15-0.50 \mathrm{~Hz}$. Vagal activity is the major contributor to the HF component while LF in some studies suggests being a quantitative marker for sympathetic modulations; other studies view the LF as reflecting both vagal and sympathetic nervous activity. The LF/HF ratio is thought to reflect sympatho/vagal balance or sometimes sympathetic modulations. How these vary during cold exposure and during rewarming may help to understand the balance in the autonomic nervous system related to risk for cold injuries (Task Force 1996).

\section{Treatment}

Treatment of frostbite includes prevention of further cold injury, hypothermia and dehydration. Protection against wind, wetness and removal of constrictive clothing or shoes are essential. In first degree superficial injury, a warm hand or warming the cold extremity in a companion's armpit or groin for 10-30 minutes can suffice. One should not rub the frozen part. Field rewarming should not be undertaken if there is a risk for refreezing, as freeze-thaw-freeze injuries cause even more damage to the tissue (Hardenberg and Ramsbottom 1969). If the frozen body part doesn't regain sensation after 30 minutes, the injury should be considered deep, and then examined and managed at a medical facility. Anti-inflammatory treatment (for example, ibuprofen $400 \mathrm{mg}$ ) should be given early, if available already in the field setting, to try to reduce the inflammatory response. 
At the medical facility, frostbitten extremities should preferably be warmed for 30-60 minutes in a $40-42^{\circ} \mathrm{C}$ recirculating water bath with a mild antibacterial agent in the solution. Rewarming is painful, and opiates are often appreciated for pain relief. Ibuprofen $400 \mathrm{mg}$ provides systemic anti-prostaglandin effect, and attenuates the inflammatory response. There continues to be a controversy over whether blisters should be left intact or debrided; some argue that blisters can be debrided and possibly covered with aloe vera-based or other topical anti-prostinoid preparations (Heggers et al. 1987), while others suggest that blisters should be left intact, as with superficial burn injuries, to diminish the risk for infection. No controlled study has yet answered this question.

Thrombolytic therapy with intra-arterial tissue plasmin activator may be benefical in patients with severe injuries where amputation is anticipated (Bruen et al. 2007; Sheridan et al. 2009; Saemi et al. 2009). The aim is to clear the microthrombosis and to restore arterial flow to normal. Angiography or technetium scintigraphy should be used to evaluate the initial injury. Angiography is used to monitor the progress of thrombolysis. Post-thrombolytic reperfusion of ischemic tissue leads to edema formation and potentially, at worst, threat of a compartment syndrome. Fasciotomy should be performed early since a compartment syndrome can be anticipated and diagnosed quickly (Hallam et al. 2010).

Several other therapies have been proposed as adjuncts to reduce tissue loss. Amongst vasodilators, intra-arterial reserpine has been shown to prevent vasospasm but does not seem to prevent tissue loss (Snider and Porter 1975). Iloprost, which is a prostglandin analogue and a powerful vasodilator, has been tried in attempts to reduce tissue loss through inhibition of platelet aggregation as well as enhancement of blood flow in the stricken extremity. Heparin has been shown to be of no benefit in specific treatment of frostbite, though it may be indicated if a frostbite victim also suffers from deep vein thrombosis. Hyperbaric oxygen therapy is controversial as a treatment for frostbite. Several animal studies have not been able to show any benefit in frostbite treatment. However, two case reports in humans have suggested that there might be some benefit if used early (von Heimburg et al. 2001; Finderle and Cankar 2002). The level of evidence so far is only anecdotal. Sympathectomy has been proposed to reduce tissue loss. It has been shown to be of benefit in a rat model with surgical division of sympathetic nerves. Pharmacologic sympathectomy in a rabbit model with procaine denervation was not effective. Sympathectomy remains controversial in humans with frostbite (Gildenberg and Hardenbergh 1964; Furman and Crimson 1948; Chandran et al. 2010, McCauley et al. 1990).

\section{Prognosis}

It has always been difficult to provide frostbite victims with an early accurate long-term prognosis of frostbite injury and disability. Experience over many decades supports the idea that amputation should be delayed until there is clear and 
distinct demarcation, and this usually means 3 to 5 weeks. If bacterial infection occurs, early limited amputation may be necessary. Technetium scintigraphy, when performed as soon as the second day after injury, can accurately predict outcome in terms of need for amputation, functional sequelae and risk for thrombosis or sepsis (Cauchy et al. 2001).

The history of Evert Stenmark in 1955 is descriptive of several of the risk factors for severe frostbite. The treatment protocol from that time has changed but even today cold takes its toll and frostbite injuries result in amputations. Better knowledge and understanding of risk factors, pathophysiology and treatment would help at least some to minimize permanent complications after frostbite which in our modern society should largely be a preventable injury. Would Evert Stenmark have had a better chance not having to amputate his feet today? He had deep frostbite, and that wouldn't have changed. The rewarming of so extensive injuries would not be accomplished in the field or at the primary health care centre. $\mathrm{He}$ would have been insulated, not allowing the extremities to thaw, then transported to a regional or tertiary hospital by the fastest possible means (air ambulance). $\mathrm{He}$ would have been rewarmed in $40-42^{\circ} \mathrm{C}$ water with cardiorespiratory monitoring and with the aid of lab analysis. He would have received potent analgesics. The vascular status in his extremities could have been described more accurately with angiography or technetium scintigraphy. It is not clear if these more advanced measures would have affected the final result of such major frostbite. It is notable; however, that such a major cold injury resulted only in foot amputation. 


\section{AIMS}

The aims of the studies were the following:

To determine incidence and contributing factors to accidental hypothermia and local cold injuries that led to hospitalization in a subarctic region

To assess the trends in diagnosis and treatment of hypothermia and local cold injury victims in a subarctic region

To determine the incidence as well as contributing factors to fatal hypothermia in a subarctic region

To determine if post-cooling hand-rewarming responses would change if measured before and after participation in 15 months of military training in a cold environment, and if this pattern of rewarming after cold provocation was related to occurrence of local cold injury

To determine if there are differences in autonomic nervous system response between individuals with normal or more pronounced vasoconstriction following cold exposure

To determine if there is an adaptation in autonomic nervous system response to cold stimuli related to prolonged cold exposure 


\section{METHODOLOGICAL ASPECTS}

\section{Ethical aspects}

For Papers I, III and IV, ethical approval for data collection, analysis, and publication was sought and received from the Regional Ethical Review Board in Umeå. For Paper II, which involved de-identified case material from the Northern Sweden database of the National Board of Forensic Medicine, no ethical approval was deemed needed for collection, analysis, and publication, though written permission was sought and received from the National Board of Forensic Medicine (Rättsmedicinalverket).

\section{Paper I}

The cohort was from the 12 hospitals in the northernmost four County Councils, where charts were collected and reviewed for specific diagnoses for 8 years, starting in 2000 and including 2007. Subjects were identified from official patient diagnosis registry for categories hypothermia (T68), frostbite (T33.0-T35.7) or near-drowning (T75.1) by the International Classification of Diseases (World Health Organisation. International Classification of Diseases (ICD-10); 2012). I also consulted the National Patient registry at the National Board of Health and Welfare (National Board 2012) to compare the annual report for events by diagnosis for the same ICD 10 identifiers. Patient records were collected and reviewed carefully by the co-authors and dedicated research nurses. On a specific data collection protocol, prospectively identified items related to hypothermia and cold injury were searched for in the patient record, and recorded when found. General patient information also was recorded. Special focus was placed on the pre-hospital and admission records, since these contained the most information about the initial patient conditions and treatments. Mild hypothermia was defined as core temperature from $35-32^{\circ} \mathrm{C}$. Moderate hypothermia was defined as core body temperature from $31.9-28^{\circ} \mathrm{C}$. Severe hypothermia was defined as core temperature less than $28^{\circ} \mathrm{C}$ (Jolly and Ghezzi 1992 ). Frostbite injuries were described by location, superficial or deep.

\section{Paper II}

The total cohort group was the population of the region, with registered cases where there was a post-mortem examination in the Forensic Medicine Department in Umeå. The modern registry of all forensic medical cases for the regions was searched to identify cases where hypothermia was classified as an underlying or contributing cause of death. The cause of death in the strict sense used in postmortem reports involves identifying the process that led to the final series of events resulting in death. A contributing factor is one where it is likely that a factor, like active coronary artery disease, could have had some effect on the final events, though it might not have been the primary inciting factor. The National Board of 
Forensic Medicine in Sweden has a regional register in Umeå for all the northern counties, and in this way we captured all the cases in the northern regions. The registry began in its modern form in 1992, and this is the reason for the date for start for inclusion in this cohort. Data for environmental temperature at the site of death were occasionally found in the accompanying police reports, though when not present there, they were identified on the register from the Swedish Meteorological and Hydrological Institute (SMHI) published city/site temperatures, which are available on the SMHI website. "Urban",'surrounding an urban area' and rural are common definitions in Sweden today, though it is not completely clear that these are optimal definitions in Northern Sweden, where there are no cities larger than 150,000 (Rural National Program for Sweden 2007-2013. 2009). Also, it is only a matter of a few short minutes in a car to get from an 'urban' area to a very sparsely populated area. Therefore, we used a two category system: urban/city where there was a population of more than 3000 local inhabitants, and 'rural' which represented a site where there were less than 3000 local inhabitants. Alcoholism, active drug abuse or medical co-morbidities as factors were obtained from medical records or from the autopsy records. "Paradoxical undressing" was defined as an irrational behaviour where a cold-exposed person undressed as a pre terminal event (Wedin et al. 1979). We further subcategorized this irrational disrobing to the following: (1) shoes off, (2) upper body undressed, and (3) lower body undressed.

\section{Paper III}

The subjects included 93 healthy young men from the Swedish Army winter warfare special forces unit in Arvidsjaur in northern Sweden. They were included at the start of their winter training schedule, which lasted 15 months. The data was collected in two sessions, before and after winter training, in 2003 and 2004. All subjects were all exposed to the same training, the same cold, and with the same protective clothing. The cold provocation and recovery test was conducted in the same standardized fashion for all subjects (Figure 1-2). Testing was conducted twice in subjects, first at the start of training, and then 15 months later for all that were available. Subjects prepared for the test by not smoking, eating, drinking coffee and tea or physically exerting themselves and no cold exposure for the 2 hours preceding the test. We asked them not to drink alcohol for the whole day prior to the test. The cold provocation and hand rewarming test, similar to the test used for feet by Ahle et al. (Ahle 1990). Infrared thermography was selected because it is well recognized and established, though usually hand rewarming is measured with a direct thermometer/thermocouple that is placed on the finger. In this study, it was elected to use an infrared camera, which is very precise and very simple. It was thought that there would be even more complete data collection if the measurement method was as simple as possible. The dominant hand is used because it is thought to be the more vascular in general, and we wanted the most vascular hand in each case. A glove was used in order to keep the hand dry. This 
is a technical aspect of controlling cooling/rewarming after the hand 'dip' is finished. If the hand was wet during the rewarming period, then there would be some evaporative cooling, and this could disturb the measurement sequence (Cleophas 1982). The hand was dipped in $10^{\circ} \mathrm{C}$ degree water for exactly 10 minutes, and then the hand was removed from the bath, and the glove taken off. Rewarming of the hand occurred based on the body's own mechanisms. The ambient temperature in the room was $22-24^{\circ} \mathrm{C}$.

Skin temperature measurements were collected with an infrared camera system (Ahle et al. 1990; Schufried and Vacariu 2000; von Bierbrauer et al. 1998) (Figures 1,2,3). Calibration measurements were conducted according to the manufacturer's specifications. The cameras that we used were borrowed from the Swedish Defence Centre for Chemical/Biological/Radiological/Nuclear Protection, and they are expensive and sensitive instruments that have been used in the Army to try to see how cool air and mist can hide thermal signature of military vehicles.

Figure 1. A stylised depiction of the experimental setup. First the hand was placed in cold water $\left(10^{\circ} \mathrm{C}\right)$ for 10 minutes, covered by a plastic glove which allowed thermal transport but kept the hand dry. Then, the hand was rested on a platform from which optimal thermal images could be recorded every 10 seconds for 30 minutes.

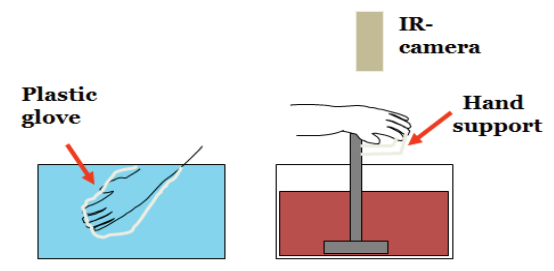

Figure 2. This healthy volunteer demonstrates one cooled hand (right, which is reddened in the rewarming phase) and one warm hand (left). He seems to be moderately entertained by the whole process.

Figure 3. Infrared image of a small child. Note the higher temperatures in the cheeks, ears and over the scalp.

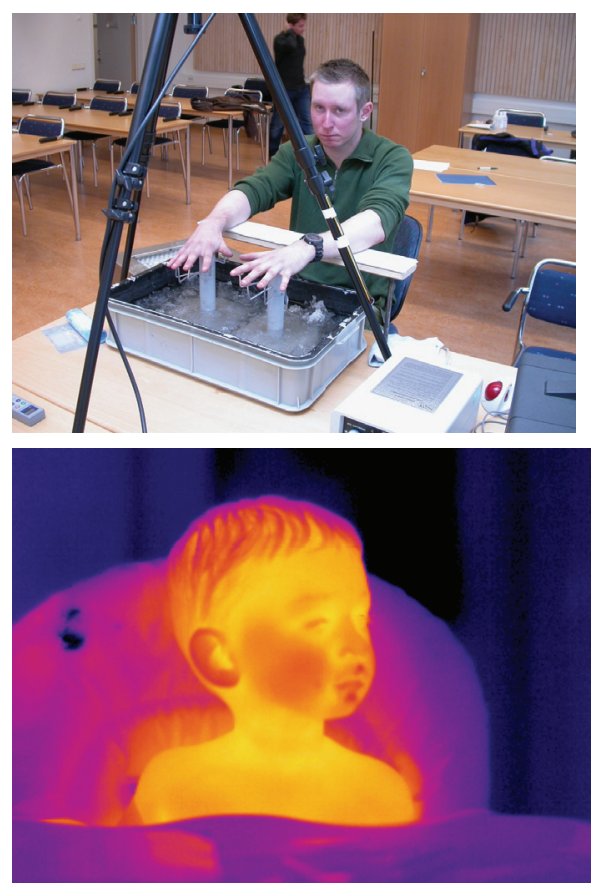


In our study, the instruments were sighted on a platform, where the subjects placed their hands (see figures 1 and 2). This platform was designed in a way that would minimize heat transfer from surrounding objects as well as the platform structure and material itself. The camera registered images at tight (every 10 seconds) intervals, which were stored and analysed later.

Thermographic rewarming responses were identified for 5 distinct points in time: At the end of the baseline period, end of 10 minutes cooling, and after 5, 15 and 30 minutes of recovery. Percentage of the 30 minute rewarming period during which the fingertips were vasodilated $(\% \mathrm{VD})$ was defined as when fingertip temperature was greater than finger base temperature.

Subjects were initially categorized into three rewarming groups, as described by Dupuis (Dupuis 1987). Rewarming categories included normal rewarming (N), $\mathrm{T}_{\text {Finger }}, 30>20^{\circ} \mathrm{C}$ and $\% \mathrm{VD}>50$; moderate rewarming $(\mathrm{M})$, either $\mathrm{T}_{\text {Finger, }}, 30>$ $20^{\circ} \mathrm{C}$ and $\% \mathrm{VD} \leq 50$, or $\mathrm{T}_{\text {Finger }}, 30<20^{\circ} \mathrm{C}$ and $\% \mathrm{VD} \geq 5$; and slow rewarming (S), $\mathrm{T}_{\text {Finger }}, 30<20^{\circ} \mathrm{C}$ and $\% \mathrm{VD}<5$.

Cold injury incidence

Each subject reported to their superior every 10 days whether or not he had suffered any cold injury during the training period. Each soldier used a cold injury reporting protocol to report, and if there was something to report, they marked on a drawing, the anatomical site and described severity using predefined keywords. Officers commented that there was likely a tendency of soldiers to both underreport and to neglect their injuries, since reporting may have been perceived by the soldiers themselves as a sign failure or underperformance in the field. A medical expert assessed reported frostbite findings, and classified them as either superficial or deep. White, numb and/or swollen fingers were considered as superficial injuries while blistered or white frozen fingers with persistent symptoms (i.e., pain and joint stiffness) were considered as deep injuries.

\section{Paper IV}

The subjects were the same as those included in Paper III, though the subjects were regrouped for this analysis. First, the initial subjects were placed in one of two groups, either slow rewarmers or normal rewarmers. In Paper III, there was a group in between, but for Paper IV, the normal rewarmers were compared to all who were delayed (in Paper III, 'moderate' and 'slow') rewarmers. ECG recordings were further analysed for heart rate variability (HRV).

There were 3 statistical analyses in this HRV material. The first was to describe that there was a HRV response (different HRV parameters) during and after the cold hand provocation. The second test was a comparison of the HRV results for normal rewarmers vs slow rewarmers at the initial cold hand provocation. The third test was to evaluate, within each group (normal rewarming or slow rewarming), if there was an effect of cold training by comparing the second test at the end 
of their duty to the first test (at entry). This third test was the main test, to try to identify adaptation in autonomic nervous system response during/after cold provocation.

Heart rate variability analysis was carried out using non-commercial programing (based in Matlab/Mathworks, Natick, MA, USA). Using an adequate electrocardiographic signal that has been recorded digitally, $\mathrm{R}$ waves can be automatically identified to find intervals between beats. There is a sorting process to eliminate artefacts or extra beats. Then, selected short (3 minute) segments are analysed separately using the frequency-domain method where variance (power) is presented in terms of frequency (or momentary heart rate). Each 3 minute segment is analysed to a spectrum of frequencies with corresponding amount of 'power' or variability. These frequencies are divided into domains which now by convention are presented as 'very low' frequency, 'low' frequency', and 'high' frequency (Task Force 1996). For brief (3 minute) measurement sequences, as we have done, these 3 domains can be identified, though the domain of 'very low' frequency is not considered reliable enough to be interpreted unless there is a much longer sequence (hours). These frequency domains strongly correspond to physiological processes, autonomic nervous system functions, which reflect regulatory effects on the circulation, among other things. For example, the high frequency domain represents events where there is a large degree of variability, and this is typical of the 'sinus arrhythmia', where with relatively lots of vagal/parasympathetic influence on the heart.

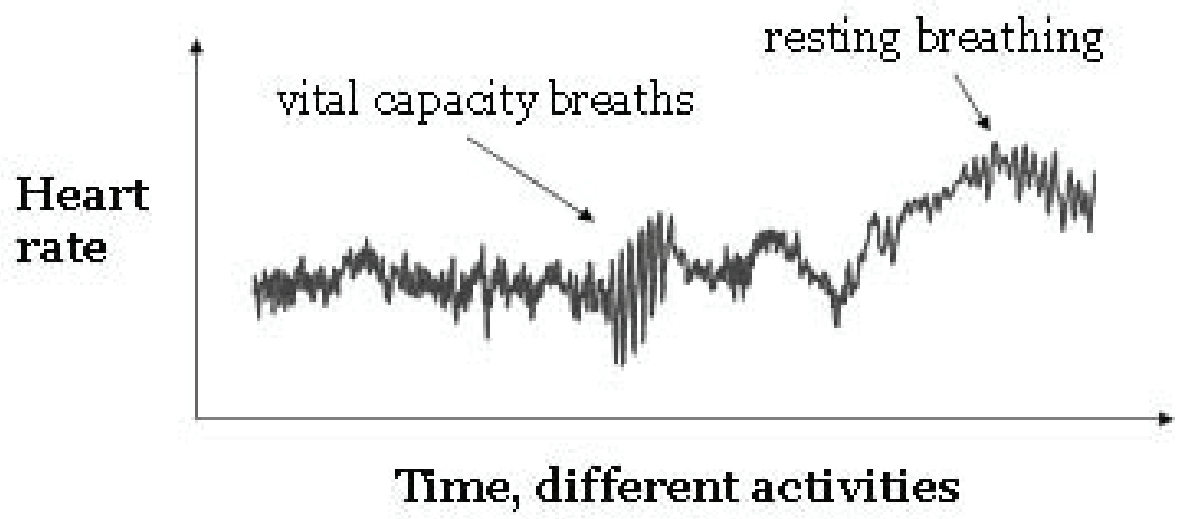

Figure 4. Absolute heart rate, and variations over time for an individual in different situations. Note how some of the variation is obviously associated with breathing, and other variation (or reduction in variation) may be less obviously related to breathing activity. 
The autonomic nervous system response to cold provocation and recovery then is what is assessed here with HRV. When there is more power in the high frequency domain, this reflects more parasympathetic influence in the autonomic nervous system effector activity regarding the circulation. Parasympathetic influence then is regarded as favouring not only more heart rate variability and lower heart rates but also vasodilation, which is expected to be more prominent in a normal rewarmer. More 'low' frequency power is thought to be strongly related to sympathetic nervous system expression involved in regulation of blood pressure (the baroreflex), or more sympathetic weight relative to parasympathetic. This would then be expected to also lead to more tendency for peripheral vascular constriction. More vasoconstriction in the setting of the cold provocation and hand temperature recovery would be expected in the slow rewarmers. The low/high frequency ratio is often presented as well, where a higher ratio describes a situation where there is relatively more sympathetic nervous system expression compared to parasympathetic nervous system expression. Total power is not a specific indicator of a particular type of autonomic nervous system activity, but rather an indicator of the total amount of variability, which is non-specific. Heart rate by itself is also commonly presented, and low heart rates in adults typically reflect prominent parasympathetic nervous system influence.

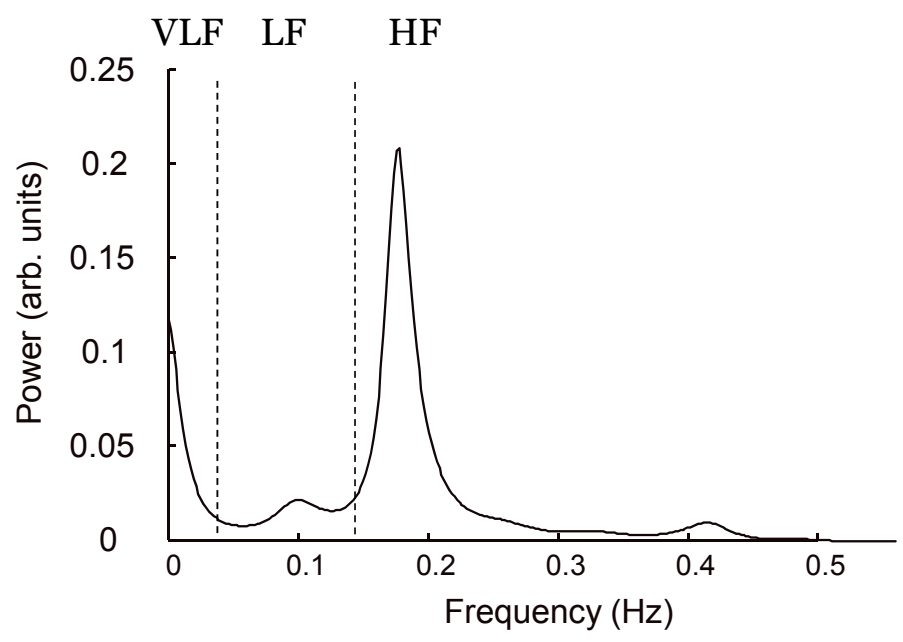

Figure 5. This stylized image shows the frequency spectrum format for analyzing heart rate variability. The $\mathrm{x}$ axis (Frequency) represents simultaneous frequency for beats, and the $\mathrm{y}$ axis represents power (for observed variation at the different frequencies). The three spectra which are of interest in assessing autonomic nervous system activity are the Very Low Frequency (VLF), Low Frequency (LF), and High Frequency (HF). 


\section{Statistics and analysis}

For Paper I, for this registry analysis, only simple linear regression and reporting or a regression coefficient was used. For Paper II, paired t-test was used, as well as a comparison of factors where one was categorical and the other numerical. For Paper III, a Fisher's exact test was used to analyse demographic results. A one-way ANOVA for independent groups was used to test for differences between baseline and recovery values as well as for pre- and posttraining values. ANOVA for repeated measures was used to test for changes in temperatures during the course of the cold-provocation and rewarming, along with a Tukey post-hoc test. Paired t testing (one-tailed) was used to compare pre- and post-training values for each rewarming group. For Paper IV, ANOVA for repeated measures was used to identify differences in serial measures of temperature, HR, and derived heart rate variability parameters. Group, time, and pre-/post-training were tested as independent factors. For post-hoc testing, paired or group-wise t testing was used. For all tests, a $\mathrm{p}$ value of $<0.05$ was used to determine significant differences. 


\section{RESULTS OVERVIEW}

\section{Paper I and II}

Concerning general incidences, there were 379 total cold injury patient admissions which we could identify by hospital codes during this period (20002007). Of these, 244 were hypothermia cases, 105 frostbite, and 75 drowning cases. This corresponds to an average annual incidence of hospitalization during this period for hypothermia of 3.4 per 100,000 inhabitants, along with 1.5 frostbite cases per 100,000, and 1.0 near-drowning cases per 100000 . For fatal hypothermia during the period of 1992-2008, there was a total of 207 cases identified from the same region ( 900,000 inhabitants), which gave an average annual incidence of 1.35 deaths per 100,000 inhabitants.

Concerning gender and age for hypothermia hospitalization, men numbered 267 $(70 \%)$ and women $112(30 \%)$. For fatal hypothermia, 149 (72\%) were men and 58 (28\%) were women. For hypothermia hospitalization, we observed a median age of 60 years for all, 57 for men and 72 for women. For frostbite, the median age for all was 52 years, for men 55, and 50 for women. Fatal hypothermia ages were 16 to 101 years, with mean age for all victims of $62 \pm 17$ (mean \pm SD), for men $61 \pm$ 16 , and for women $65 \pm 17$ years.

For cold injury hospitalization, there were many different pre-morbid or preinjury activities described, with none being predominant. The majority had no recorded activity to be found in the hospital journal. It was more difficult to assess the pre-morbid activities for most fatal hypothermia victims. The majority $(72 \%)$ occurred in rural settings, most (93\%) were found outdoors, and most close to a house or building.

Temperature outside was not captured in the hypothermia hospitalization cohort material. For the fatal hypothermia, outside temperature at the site for the presumed time of death was recorded in the police report in only a fraction of the cases $(23 \%)$. The reason for this lack of documentation was unclear. We reconstructed these temperatures. For 36\%, the ambient average daily temperature then was above $0{ }^{\circ} \mathrm{C}$, and $5 \%$ occurred with ambient temperatures below $-20^{\circ} \mathrm{C}$.

Exposure to water, or immersion was involved as near-drowning in $8 \%$ of hypothermia hospitalization cases and as cold immersion in $27 \%$ of the fatal hypothermia cases, which demonstrates how dangerous immersion is in cold climate.

Concerning grade of hypothermia in hypothermia hospitalization, temperature was measured and recorded at the accident site for only $13 \%$. In the hospital it was documented in the chart for almost all (96\%), but the temperature measurement method and the site of measurement were seldom registered. Severe hypothermia $\left(<28^{\circ} \mathrm{C}\right)$ was noted for $24 \%$, moderate hypothermia $\left(31.9-28^{\circ} \mathrm{C}\right)$ was noted for $40 \%$, and mild hypothermia $\left(35-32^{\circ} \mathrm{C}\right)$ was noted for $20.5 \%$. Some patients were 
treated for hypothermia although no temperature below $35^{\circ} \mathrm{C}$ was noted in the chart. For these, it can be presumed that they had mild hypothermia.

Table 1. Co-morbidities, co-factors

\begin{tabular}{lcc}
\hline & $\begin{array}{c}\text { Hypothermia } \\
\text { (paper 1) }\end{array}$ & $\begin{array}{c}\text { Fatal hypothermia } \\
\text { (paper 2) }\end{array}$ \\
\hline Ischemic heart disease & $19 \%$ & $32 \%$ \\
Cerebrovascular disease & $6 \%$ & $6 \%$ \\
Multiple trauma & $5 \%$ & $4 \%$ \\
Psychiatric illness & $7 \%$ & $14 \%$ \\
Dementia & $9 \%$ & $15 \%$ \\
Epilepsy & $2 \%$ & $4 \%$ \\
Suicide attempts/ apparent suicide & $5 \%$ & $5 \%$ \\
\hline
\end{tabular}

For the hypothermia hospitalization cohort compared to fatal hypothermia cohort, comorbidities were similar. Alcoholism was noted in the post-mortem report for $35 \%$ of the cases, while the word alcoholism was not observed in the hospital charts. Drug presence was noted as lab results in a following paragraph.

Concerning physical findings for fatal hypothermia at post-mortem examination, those that are specific to hypothermia include excoriations to hand and forearms (thought to be due to the last physical effort to get oneself out of the dangerous situation) and gastric excoriations due to local ischemia (Takada et al. 1991) or possibly direct cold injury. Pancreatitis as a post-mortem finding was infrequent in our cohort.

Laboratory results included electrocardiographic findings that showed few malignant dysrhythmias. The most common dysrhythmia was atrial fibrillation, which occurred for individuals mostly in mild or moderate hypothermia. Laboratory findings showed disturbances in arterial blood gas data, coagulation profile, blood cell counts, and electrolytes. 
Results overview

Table 2. Laboratory results (hypothermia group, $n=244$ ).

\begin{tabular}{|c|c|c|c|c|}
\hline & & $n=$ & Median & $\min -\max$ \\
\hline \multicolumn{5}{|l|}{ Arterial blood gas } \\
\hline $\mathrm{HbO}_{2}$ sat & $(\%)$ & 90 & 97 & $75-100$ \\
\hline $\mathrm{pO}_{2}$ & (Kpa) & 63 & 12,9 & $1.2-55$ \\
\hline $\mathrm{pCO}_{2}$ & (Kpa) & 63 & 5,8 & $1.4-14.6$ \\
\hline $\mathrm{pH}$ & & 70 & 7,29 & $6.60-7.52$ \\
\hline \multicolumn{5}{|c|}{ Hemostasis, coagulation } \\
\hline platelets & $\mathrm{x} 1000 / \mu \mathrm{L}$ & 169 & 236 & $41-456$ \\
\hline PT INR & & 113 & 1,0 & $0.10-7.00$ \\
\hline $\mathrm{APTT}$ & seconds & 96 & 24,7 & $17-88$ \\
\hline \multicolumn{5}{|l|}{ Blood counts } \\
\hline $\mathrm{Hb}$ & $g / L$ & 189 & 143 & $41-186$ \\
\hline Hematocrit & $\%$ & 174 & 42 & $20-53$ \\
\hline WBC & $\times 10^{\wedge} 9 / L$ & 158 & 11,85 & $1.2-30.5$ \\
\hline \multicolumn{5}{|l|}{ Electrolytes } \\
\hline $\mathrm{Na}^{+}$ & $\mathrm{mmol} / \mathrm{L}$ & 175 & 142 & $126-153$ \\
\hline $\mathrm{K}^{+}$ & $\mathrm{mmol} / \mathrm{L}$ & 177 & 4,2 & $2.3-8.3$ \\
\hline creatinine & $\mathrm{mol} / \mathrm{L}$ & 174 & 83,5 & $31-461$ \\
\hline
\end{tabular}

$\mathrm{HbO}_{2}$ sat- oxyhemaglobin saturation, $\mathrm{pO}_{2}$ - partial pressure oxygen, $\mathrm{pCO}_{2}$ - partial pressure carbon dioxide, PT INR - prothrombin time international normalized ration, APTT - partial thromboplastin time, $\mathrm{Hb}$ - hemoglobin, WBC - white blood cell count, $\mathrm{Na}^{+}$- serum sodium concentration, $\mathrm{K}^{+}$- serum potassium concentration.

The most notable laboratory findings were huge variations in hemoglobin concentrations, in $\mathrm{pH}$ and a frequent observation of hyperkalemia at some point during the hypothermia or rewarming period. Coagulation abnormalities were most frequently manifest as thrombocytopenia. 
Results overview

Table 3. Blood test results, above and below normal limits.

\begin{tabular}{llllc}
\hline & & & $\mathrm{n}=$ & $\%$ \\
\hline $\mathrm{Hb}$ & $\mathrm{g} / \mathrm{L}$ & $<117$ & 84 & 34.4 \\
$\mathrm{Hb}$ & $\mathrm{g} / \mathrm{L}$ & $117-153$ & 107 & 43.9 \\
$\mathrm{Hb}$ & $\mathrm{g} / \mathrm{L}$ & $>153$ & 53 & 21.7 \\
& & & & \\
$\mathrm{~K}^{+}$ & $\mathrm{mmol} / \mathrm{L}$ & $<3.5$ & 17 & 7.0 \\
$\mathrm{~K}^{+}$ & $\mathrm{mmol} / \mathrm{L}$ & $3.5-4.4$ & 111 & 45.5 \\
$\mathrm{~K}^{+}$ & $\mathrm{mmol} / \mathrm{L}$ & $>4.4$ & 116 & 47.5 \\
& & & & \\
$\mathrm{pH}$ & & $<7.35$ & 52 & 21.3 \\
$\mathrm{pH}$ & & $7.35-7.45$ & 15 & 6.1 \\
$\mathrm{pH}$ & & $>7.45$ & 177 & 72.5 \\
& & & & \\
$\mathrm{platelets}$ & $\times 1000 / \mu \mathrm{L}$ & $<165$ & 106 & 43.4 \\
$\mathrm{platelets}$ & $\times 1000 / \mu \mathrm{L}$ & $165-387$ & 130 & 53.3 \\
$\mathrm{platelets}$ & $\times 1000 / \mu \mathrm{L}$ & $>387$ & 8 & 3.3 \\
\hline
\end{tabular}

$\mathrm{Hb}$ - hemoglobin, $\mathrm{K}^{+}$- serum potassium concentration.

Positive drug analysis for patients surviving hypothermia compared to fatal hypothermia cases comprised: benzodiazepines $5 \%$ vs. $8 \%$, opiates $1 \%$ vs. 3 , major sedative/anti-depressives $<1$ vs. $8 \%$, amphetamine $2 \%$ vs. $4 \%$, ethanol $34 \%$ vs. $43 \%$, respectively.

Data concerning rewarming strategies were sparse. Most patients (68\%) in the hypothermia hospitalization cohort were actively rewarmed. Of the total 379 in the hypothermia hospitalization cohort, 15 patients succumbed eventually due to complications to their admission diagnosis.

The rural setting was analysed carefully for the fatal hypothermia cohort, since the victim was not rescued. In the hospitalized hypothermia cohort, the victims were all rescued and removed from the site as quickly as possible, and focus was more on the victim's activity rather than their location.

Concerning proximity of the fatal hypothermia victim to buildings or other people, 35\% were within 100 meters of an occupied building. Paradoxical undressing was noted in $30 \%$ of all cases, which was more than expected. 
Paradoxical undressing: radius of garments from victim

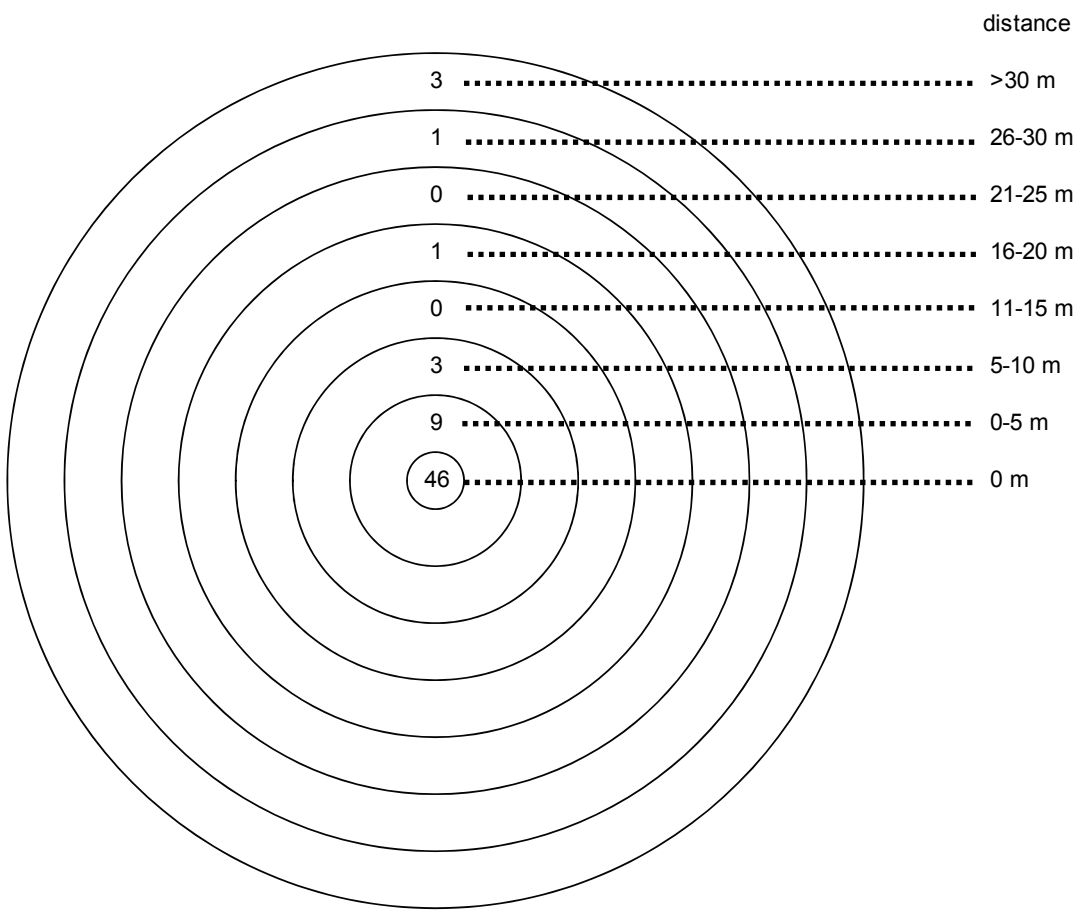

Figure 6. Pardoxical undressing. The distances for clothing dropped after disrobing, related to the final resting place, are shown, with the number of cases given for each distance interval.

\section{Papers III and IV}

Finger temperatures were successfully measured during all the measurement sequences. An example of the thermal imaging and automation in temperature reading is shown in the Figure 7 . Temperatures among fingers were generally uniform.

Rewarming results were placed in 3 categories: normal-, moderate-, and slowrewarmers, based on the experience (Dupuis 1987) that some people are very slow in their rewarming process, and that this may reflect a less effective post-cold provocation vasodilatory phase, and less effective rewarming. 'Normal' was the term given to the most effective rewarmers at 30 minutes; the Tfinger 30 was more than $20^{\circ} \mathrm{C}$ and percent vasodilation (\%VD) over $50 \%$. 


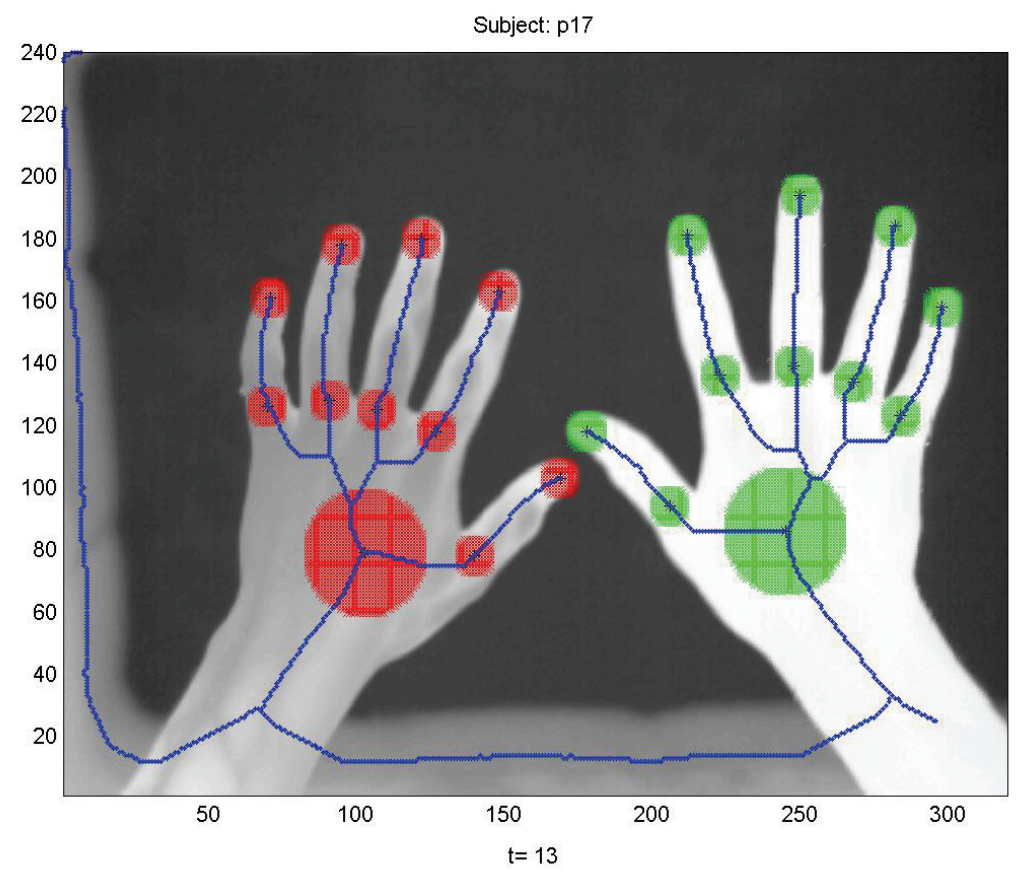

Figure 7. Thermal imaging of hands. This example of raw thermographic imagery demonstrates that both hands are imaged. Selected points in the cooled hand (the dominant hand, which happened to be the left in this subject) are identified and temperature is serially measured. The measurement indicates a fingertip temperature of $13^{\circ} \mathrm{C}$, which suggest that this image is performed at the point when cooling has ended, and the hands are first placed on the platform.

The term 'normal' could have been exchanged for 'fastest' or 'most effective', since one cannot state with certainty that the other groups were abnormal. At the pre-training test, comparison of baseline temperatures for the 3 groups showed that the 'slow' rewarmers started at a lower temperature $\left(27.3 \pm 2.9^{\circ} \mathrm{C}\right)$ compared to the 'normal' group $\left(31.1 \pm 2.3^{\circ} \mathrm{C}\right)$.

All 3 groups had approximately the same hand temperature at the start of the rewarming phase. 


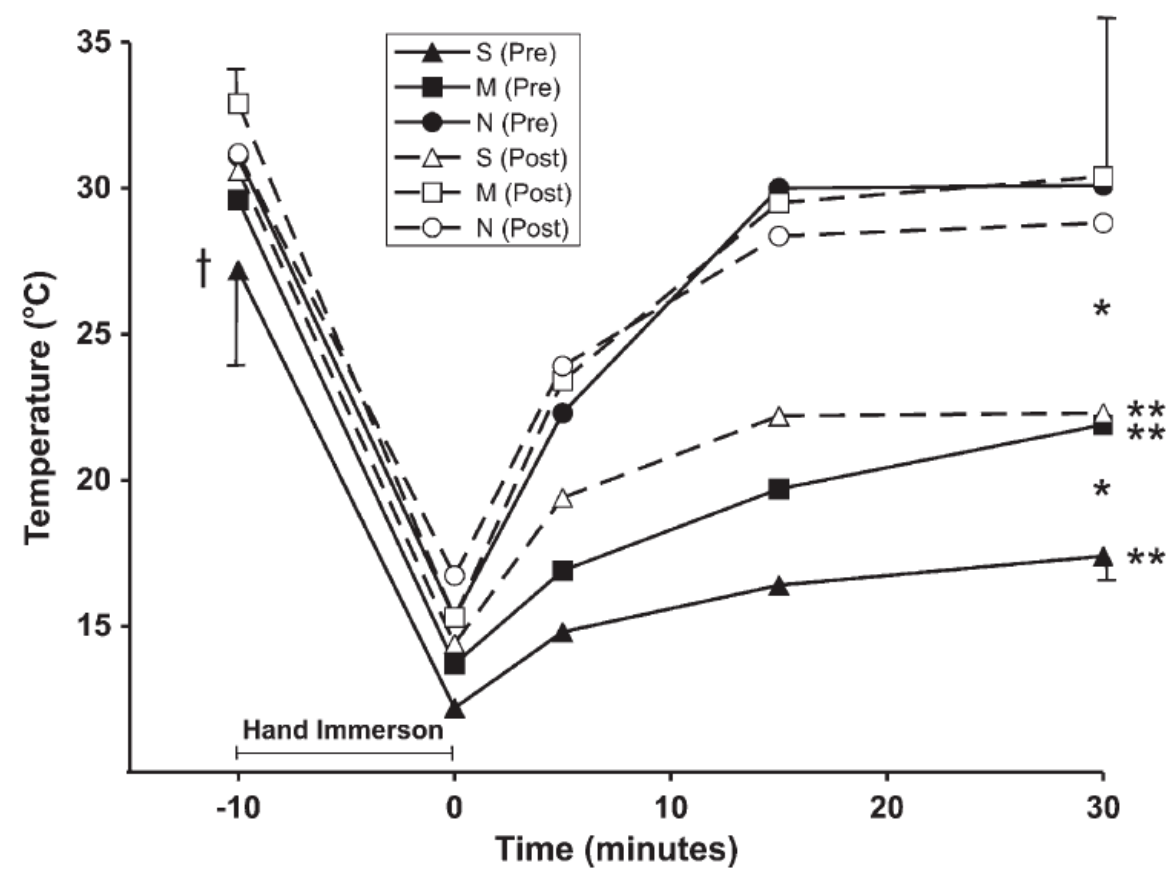

Figure 8. (From Paper III) Finger temperatures for the 3 groups with error bar representing standard deviation. Filled triangle- 'slow' rewarmers/pre-training, open triangle- 'slow' rewarmers/posttraining, Filled square- 'moderate' rewarmers/pre-training, open square- post-training/moderate rewarmers, filled circle- 'normal' rewarmers/pre-training, open circle- 'normal' rewarmers/posttraining.

$\dagger$ - the 'slow' rewarmer baseline value (pre-training) was less than those for 'moderate' or 'normal' groups (one way ANOVA).

* indicates that post-training values (at 30 minutes) were greater for 'moderate' and 'slow' groups compared to pretraining values (paired $t$ test).

** indicates that the 30 minute rewarming temperatures were less than baseline (one-way ANOVA for independent measures) 
Table 4. Pre- and post-training fingertips baseline temperatures and cold recovery variables $($ mean $\pm \mathrm{SD})$ and $(95 \%$ confidence intervals of the mean) for normal $(\mathrm{N})$, moderate $(\mathrm{M})$ and slow $(\mathrm{S})$ rewarmers. (from Table 1, Paper III)

\begin{tabular}{|c|c|c|c|}
\hline Variable & Group & Pre-Training & Post-Training \\
\hline \multirow[t]{3}{*}{$\mathrm{T}_{\text {baseline }}\left({ }^{\circ} \mathrm{C}\right)$} & $N(N=26)$ & $\begin{array}{c}31.1 \pm 2.3 \\
(30.2,32.1)\end{array}$ & $\begin{array}{c}31.1 \pm 5.3 \\
(29.0,33.4)\end{array}$ \\
\hline & $M(N=11)^{*}$ & $\begin{array}{r}29.6 \pm 2.9 \\
(27.6,31.5)\end{array}$ & $\begin{array}{r}32.9 \pm 1.5 \\
(31.9,34.0)\end{array}$ \\
\hline & $\mathrm{S}(N=8)^{*}$ & $\begin{array}{l}27.3 \pm 2.9^{\dagger} \\
(24.9,29.7)\end{array}$ & $\begin{array}{l}30.6 \pm 3.2 \\
(27.7,33.6)\end{array}$ \\
\hline \multirow[t]{3}{*}{$\mathrm{T}_{\text {Finger, } 30}\left({ }^{\circ} \mathrm{C}\right)$} & $N(N=26)$ & $\begin{array}{r}30.1 \pm 2.4 \\
(29.1,31.1)\end{array}$ & $\begin{array}{l}28.8 \pm 6.5 \\
(26.2,31.4)\end{array}$ \\
\hline & $M(N=11)^{*}$ & $\begin{array}{c}* * 21.9 \pm 4.4^{+} \\
\quad(19.0,24.8)\end{array}$ & $\begin{array}{r}30.4 \pm 6.4 \\
(26.1,34.7)\end{array}$ \\
\hline & $\mathrm{S}(N=8)^{*}$ & $\begin{array}{c}* * 17.4 \pm 0.4^{t+} \\
(17.1,17.8)\end{array}$ & $\begin{array}{c}* * 22.3 \pm 6.8^{\dagger+} \\
(16.6,28.1)\end{array}$ \\
\hline \multirow[t]{3}{*}{$\%_{\mathrm{VD}}(\%)$} & $N(N=26)$ & $\begin{array}{l}81.3 \pm 13.8 \\
(75.7,86.9)\end{array}$ & $\begin{array}{l}66.8 \pm 38.3 \\
(51.3,82.2)\end{array}$ \\
\hline & $M(N=11)^{*}$ & $\begin{array}{l}27.5 \pm 15.5^{\dagger} \\
(17.0,37.9)\end{array}$ & $\begin{array}{l}65.9 \pm 33.5 \\
(43.4,88.4)\end{array}$ \\
\hline & $\mathrm{S}(N=8)^{*}$ & $\begin{array}{c}0.7 \pm 1.5^{+\dagger} \\
(-0.5,2.0)\end{array}$ & $\begin{array}{l}31.7 \pm 44.2 \\
(-5.2,68.6)\end{array}$ \\
\hline
\end{tabular}

Data are from the 45 rangers who were successfully tested pre- and posttraining. $T$ baseline is fi ngertip temperature just prior to immersion in $10^{\circ} \mathrm{C}$ water; $\mathrm{T}$ Finger, 30 is the fingertip temperature after $30 \mathrm{~min}$ of rewarming; and \% vD is the percentage of the 30-min rewarming period during which fingers were vasodilated (that is, fingertip temperature was greater than at the base of the finger).

$*$ post-training value greater than pre-training value. ${ }^{\dagger \dagger}$ less than for $\mathrm{M}$ and $\mathrm{N}$ groups; ${ }^{\dagger}$ less than for $\mathrm{N}$ group. ** less than $\mathrm{T}$ baseline within group $(P, 0.05)$.

After cold training, baseline temperatures were higher in the 'slow' and 'moderate' groups, but not in the normal group, leading to the observation that baseline temperatures (before the cold provocation) did not differ between groups. There were also alterations in the rewarming pattern for the 'slow' and 'moderate' groups (increase in rewarming temperatures, towards the normal), but not for the normal group. These observations support the idea that cold training improved the vasodilatory response and thus the rewarming function for the slow and moderate groups, but not for the normal group.

In this study, 5 of the subjects reported cold injuries, and $4 / 5$ were in the 'slow' rewarming group. These are small numbers of observations, but a crude analysis (Fisher's exact test) allowed an interpretation that cold injury was more common in the 'slow' rewarmer group. 
A traditionally recognized risk for impaired vasodilatory responsiveness is tobacco use (Munjal et al. 2009), and we tried to identify tobacco use in these subjects. Regular tobacco use (for these subjects, it was smokeless tobacco) showed not significant association to cold injury of 'slow' rewarming. This finding was not definitive, since the number of observations was small, and the study protocol for cold provocation and thermography tried to eliminate the effects of recent intake of vasoactive substances.

The subjects and cold-provocation from Paper III were also the basis for Paper IV. The 'normal' rewarming group, based on finger temperatures at 30 minutes rewarming, was compared to all others, which were grouped into a single category of 'slow' rewarmers. This was done in order to allow paired analysis of heart rate variability (HRV) parameters. Comparing more than 2 groups for this type of multi-parameter results, also with repeated measures, would not have been readily feasible from a mathematical standpoint, and would not have been clear enough from a hypothesis testing perspective.

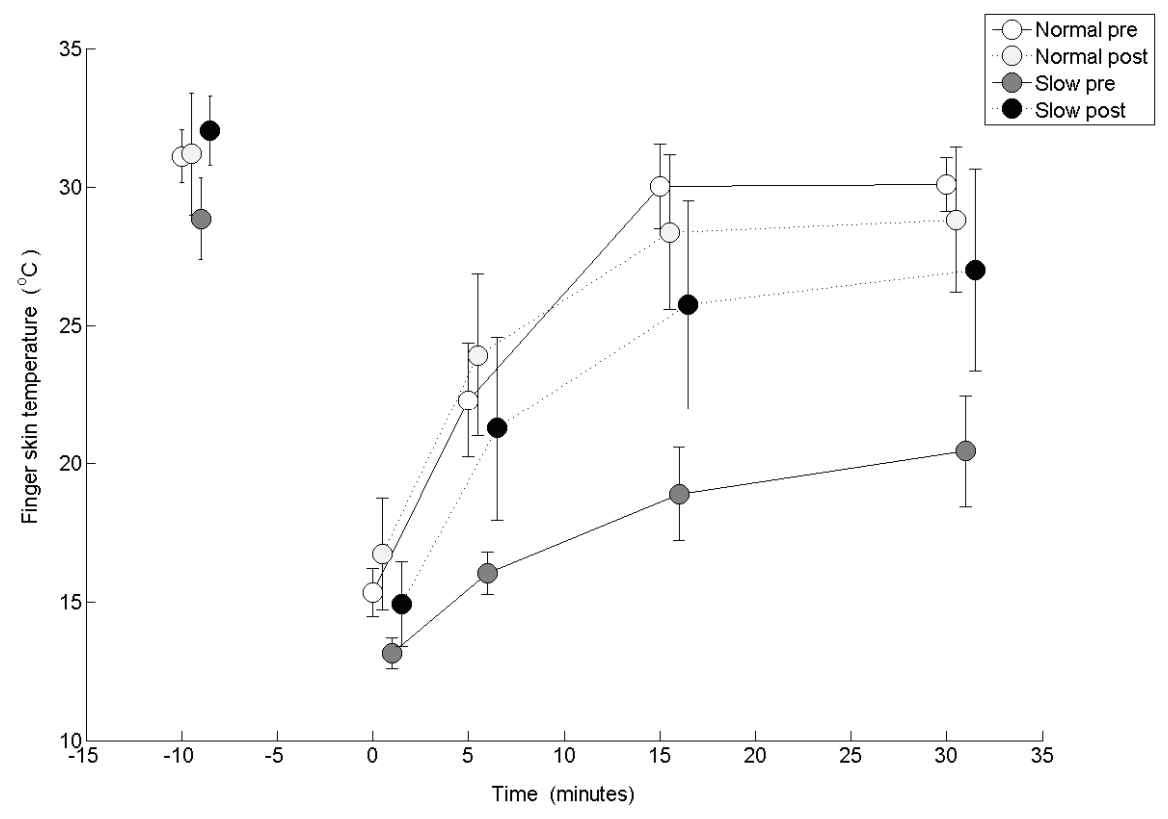

Figure 9. Temperature measurements shown for the 2 groups: open circle - 'normal' group/prewinter training, light gray-filled circle - 'normal' group/post-winter training, dark gray-filled circle 'slow' group/pre-winter training, black-filled circle - 'slow group/post winter training. (from Figure 1, Paper IV)

Heart rate variability parameters were derived from the 3-minute segments from each prospectively identified part of the cold provocation and rewarming periods. 
An overview of a single heart rate signal over time can be seen for 2 individual subjects (lower panels, figure below). From these raw heart rate signals, the complex mathematical analysis provides a set of variability markers for each 3minute period. The peak values for the domains are then presented for the 'total', the 'high' frequency domain, and the 'low' frequency domain, for each 3-minute sequence (figure 10, lower panels).
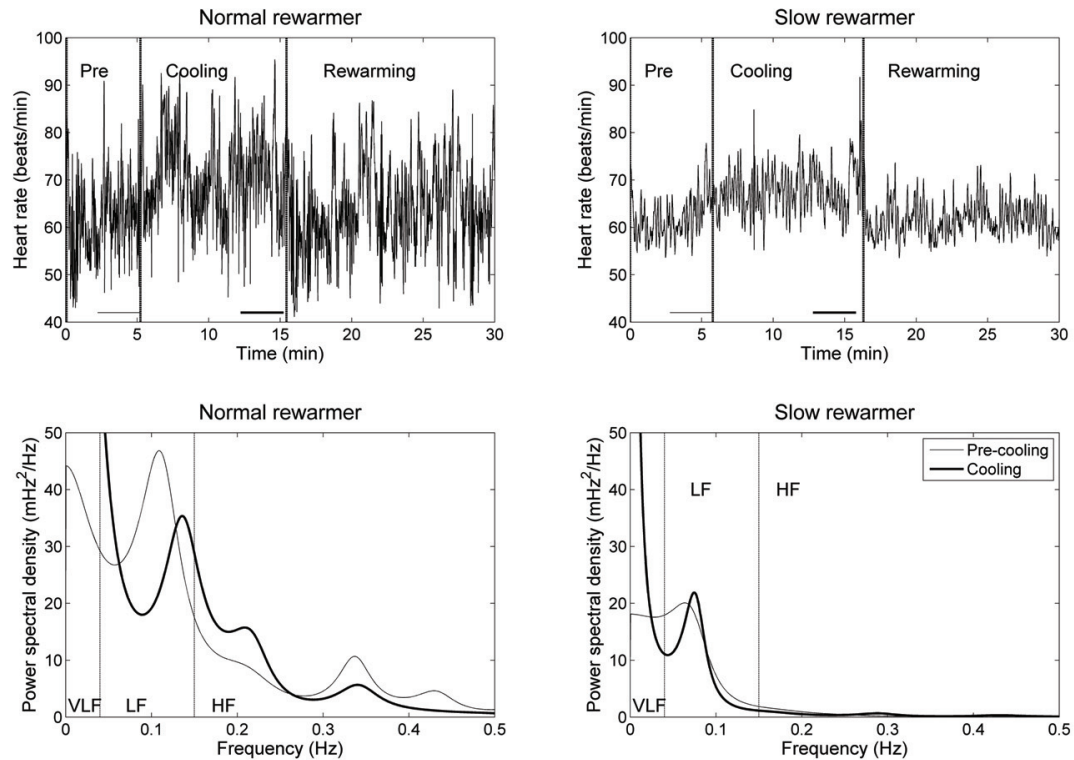

Figure 10. Raw heart rate and variability data from 2 subjects. In the left 2 panels, a normal rewarmer shows heart rate changes which are more pronounced even to the naked eye compared to a slow rewarmer in the right panels. The analysis for heart rate variability (HRV) for the normal rewarmer showed more total variability in all ranges of frequency, and more high frequency (HF) variability compared to the slow rewarmer. The shadowed line in the lower panels represents the precooling HRV result, and the dark line represents the HRV results during cooling.

The pretraining observations showed no difference between the 'normal' and 'slow' rewarming groups for resting heart rate before the provocation, but there were differences for some of the HRV parameters: $\mathrm{P}_{\mathrm{HF}}$ was higher in the normal group, and PLF/HF was lower in the normal group, both supporting the idea that there was more parasympathetic influence in the normal group before the cold provocation (pre-training). There are multiple parameters that change generally in the same direction during the cold provocation and recovery period, where the main difference between groups seemed to occur with $\mathrm{P}_{\mathrm{HF}}$ (lower in the 'slow' rewarmer group throughout the provocation and recovery period).

In the post-training, both groups seemed to have altered their response to the cold provocation. They both had less heart rate increase in response to the cold 
hand insult. For both the 'normal' and the 'slow' rewarmer groups, HRV parameters were generally lower after winter training, but this effect seemed to be more pronounced in the 'slow' rewarmer group, particularly for $\mathrm{P}_{\mathrm{LF}}$ and $\mathrm{P}_{\mathrm{HF}}$ parameters.

There was significant drop-out from the initial set of subjects, and it is unclear if any aspect of temperature tolerance could have been involved in this dropout.

Pre-training and post-training results are given in Paper IV for the separate groups ('normal' and 'slow' rewarmers). Single measures (averages) are shown in tabular form (see table below).

Table 5. Heart rate variability results (average values for whole provocation) for pre- and post-winter training. (from Table 1, Paper IV)

\begin{tabular}{|c|c|c|c|c|}
\hline & \multicolumn{2}{|c|}{ Normal rewarmers $(n=24)$} & \multicolumn{2}{|c|}{ Slow rewarmers $(n=19)$} \\
\hline & Pre-training & Post-training & Pre-training & Post-training \\
\hline HR (beats/min) & $73.6 \pm 7.1$ & $72.6 \pm 7.1$ & $75.0 \pm 8.1$ & $72.1 \pm 7.7$ \\
\hline $\mathrm{P}_{\mathrm{tot}}\left(\mathrm{mHz}_{\log }^{2}\right)$ & $4.00 \pm 0.24$ & $3.89 \pm 0.24$ & $4.00 \pm 0.18$ & $3.89 \pm 0.25$ \\
\hline $\mathrm{P}_{\mathrm{LF}}\left(\mathrm{mHz}_{\mathrm{log}}^{2}\right)$ & $3.64 \pm 0.22$ & $3.47 \pm 0.24$ & $3.65 \pm 0.20$ & $3.50 \pm 0.28$ \\
\hline $\mathrm{P}_{\mathrm{HF}}\left(\mathrm{mHz}_{\log }^{2}\right)$ & $3.29 \pm 0.37$ & $3.17 \pm 0.38$ & $3.19 \pm 0.27$ & $3.10 \pm 0.31$ \\
\hline $\mathrm{P}_{\mathrm{LF}} / \mathrm{P}_{\mathrm{HF}}$ & $0.35 \pm 0.24$ & $0.30 \pm 0.26$ & $0.46 \pm 0.28$ & $0.40 \pm 0.28$ \\
\hline
\end{tabular}

It is illustrative to compare all subjects combined, shown here (Table 5, above) for pre-training and post-training HRV results, even if a 'slow' or 'normal' group characteristic might be diluted. These results support the idea that cold training leads to an adaptation in the autonomic nervous system response to an acute cold provocation. The observations suggest that some individuals respond more than others, but even the 'normal' responders showed some degree of adaptation in parasympathetic and sympathetic nervous system interaction when responding to a cold insult. 

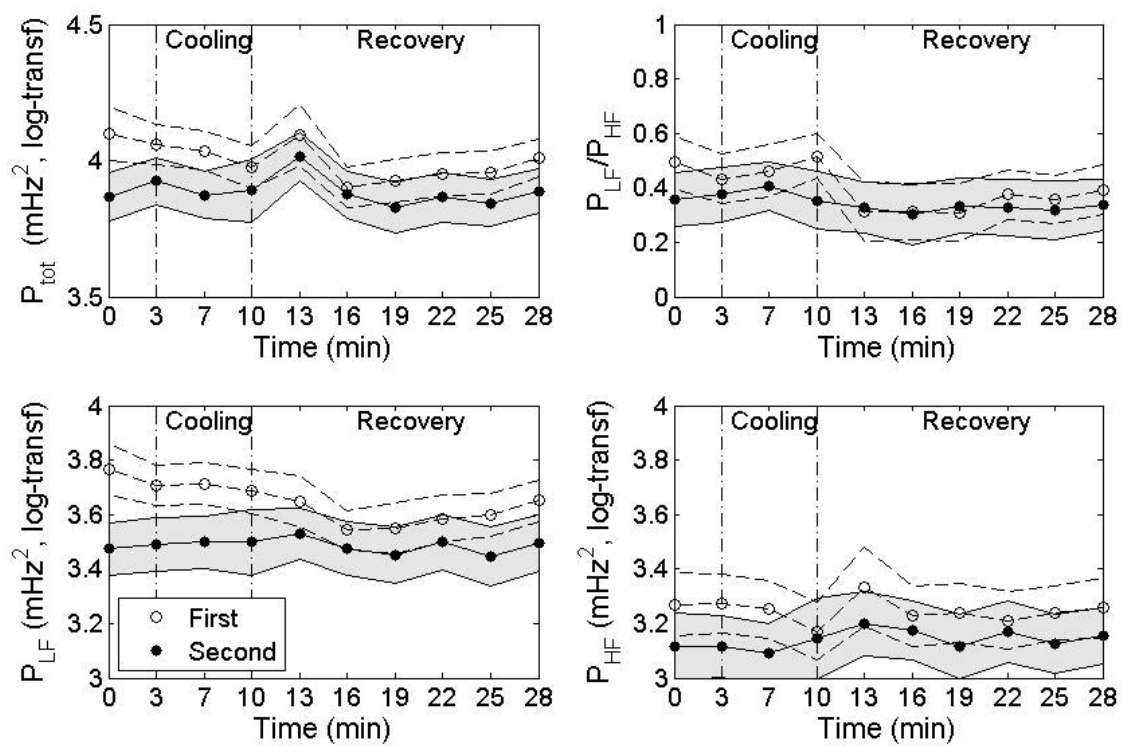

Figure 11. HRV parameters for combined ('normal' and 'slow' groups), before (First) and after (Second) winter training. The mean values are shown here, with $95 \%$ confidence intervals shown as within solid (shaded area) or hatched (non-shaded area) lines. The test performed after winter training (Second, in the legend) shows mostly lower HRV values, both from the resting start, and also during many points in the cold provocation and recovery sequence. Note that the scale is logarithmic. Note that these groups represent the combination of all normal and slow rewarmers into one group, with results shown for before and after winter training. This is in contrast to the corresponding 2 figures in Paper IV, which show the same results but for the separate groups, normal and slow rewarmers. 


\section{DISCUSSION}

These studies have tried to identify different types of risk that seem to be involved in cold injury. These risks include environmental, behavioural, comorbid illnesses or injuries, but also individual variation in how one tolerates or responds to cold.

These results support the idea that cold injury is a threat to individuals in our region throughout the year. There seems to be predominance for cold injury in individuals of middle age- it is not just a problem for the elderly adults. Severe cold injuries seem to be frequently coupled to other serious medical conditions. Hypothermia deaths occur frequently in close proximity to potential help. Autonomic nervous system responses to cold insult in healthy individuals have been examined, but this type of assessment may be even more relevant in individuals with serious medical pre-conditions.

\section{Clinical and organisational implications}

Paper I showed the degree of morbidity that occurs related to accidental cold injury. There is quite a lot of morbidity, which not infrequently leads to disability or even death. There is a large community impact of this morbidity. There are implications both for how effective we are with preventive measures, but also how we allocate health care resources. When risk groups can be identified, then more focused interventions can be designed and implemented. There is a very large risk related to alcohol use and cold injury, though trying to reduce alcohol related injury has always been a difficult area for policy makers. Increased taxation on licensed alcohol has not generally succeeded in reducing alcohol intake, where there is relatively abundant non-licensed alcohol production and distribution. Despite this, there should be some means of preventing many hypothermia deaths in individuals with alcohol overuse or misuse. Vehicular accidents and hypothermia should be an area of interest, where for example, access to snowmobiles could potentially be coupled to alcohol breathalyzer-coupled ignition systems.

Concerning diagnosis and treatment programs for accidental hypothermia, there are many different separate challenges. We have observed that the success rate with accurately measuring core body temperature in the prehospital setting in individuals where hypothermia is strongly suspected has been low. One major reason for this is that there seems to be no general agreement on an adequate thermometer for this purpose in the pre-hospital setting. In my view, there is really only one device that uses a method that is adequate for pre-hospital measurement of core body temperature, and this is the closed-ear canal thermometer. This device has been known to be a bit uncomfortable (for patients) in its clinical application. Infrared methods have been shown to be unreliable in outdoor settings. This closed-ear canal method provides more reliable readings, but the device has not been steadily in production in recent times. It seems that patient complaints about 
discomfort during temperature measurement have led to limited interest in the device by ambulance systems. Another aspect of temperature measurement concerns ambulance system interest in temperature measurement. In an ambulance system where there are generally shorter transportation times, and correspondingly less health care delivered in the pre-hospital setting (with the goal of getting the patient to the hospital in the shortest possible time), perhaps temperature measurement is less of a priority. But, where there must be careful and sometimes aggressive care delivered in the field, and where a patient is suspected to be hypothermic, then knowing a patient's core body temperature is an important aspect in helping to determine proper interventions. Given the relatively sparsely populated situation for most of Sweden, this issue should probably be addressed by a national agency, rather than being left to individuals.

Treatment routines for this cohort in Paper I were difficult to evaluate since there was so little documentation that resulted in data collection. From what could be observed, there were no clear routines, even though most hypothermia victims were actively rewarmed. The different vital organ system dysfunction that occurs, and the experience with rapidly changing conditions during rewarming can lead on to think that a systematic treatment program, with detailed documentation, would be of benefit to patients, as well as support for the responsible health care workers.

Documentation is important when trying to retrospectively study clinical events. A treatment protocol provides a guide to support documentation, even for inexperienced clinicians. For this study (Paper I), there were many missing items in our data collection. In the data collection sheet, the same format was used for searching the individual patient charts. This data collection tool was created when the study was designed, where the co-investigators tried to be comprehensive for all relevant hospital chart information that was practically or theoretically linked to hypothermia. There were several individuals (myself and supervisors, and four research nurses, all familiar with hypothermia through teaching or management of hypothermia as a clinical problem) involved in the actual chart review, which was conducted in each hospital (12 different hospitals). In that way, I believe that there is minimal variation in the way that the charts were reviewed. Some (maybe half) of the hospital charts were dictate-typed notes, and the other half were digitized/ computerized records, which also can contribute some to variability. One aspect of the data collection strategy was that there were many separate items, including many items that occurred with low frequency. One aim of the study design was to find some of the low frequency occurrences. Another aspect was to try to identify trends where correct treatment led to better outcome, and treatment that was inconsistent with current understanding of the pathophysiology might have lead to worse outcome. One example is that physically or mechanically rough handling is sometimes not well tolerated in hypothermia victims. At low core body temperatures, there is not a lot of well-established evidence for exactly how to treat, particularly in the field, concerning either ventilatory or circulatory support, 
or drug doses. Once cardiopulmonary resuscitation is initiated, it is difficult to find a balance between adequate compressions and compressions which are minimally traumatic in a non-compliant chest. In the hypothermic setting where coagulopathy is expected, further injury sustained during rescue or cardiopulmonary resuscitation may lead to bleeding, though rescue and life-sustaining interventions cannot be put aside because of this risk. Where victims have developed ventricular fibrillation during the rescue, it can never be ascertained if the malignant dysrhythmia would not have occurred if the rescue had been conducted another way. Still, we must have treatment goals, and practical descriptions of how to try to achieve them while minimizing risk of injury related to the treatments themselves. For example, in this setting, probably the automated chest compression devices should be implemented only with extreme caution, since they are designed and calibrated for effects in normothermic individuals.

Paper II analysed a cohort of hypothermia fatalities, and the possibility to examine survivors and fatalities from the same kind of accident presented some promise for identifying characteristics which might favour survival or death. In comparing pre-hypothermia risk factors, it seems that there are strong similarities between the non-surviving and the surviving group. There was a high incidence of hypothermia deaths in individuals that were known to be alcoholics. It is not clear if their general condition had deteriorated significantly in the weeks and days before they succumbed to hypothermia, or if this was an event associated mostly with acute intoxication.

Psychiatric illness and dementia also seem to be a prominent subgroup of those that are victims of cold injury. For both of these, there is poor individual insight into their illness and limitations. Therefore, preventive steps for life-threatening exposure are taken by others in their presence. One interpretation of the findings is that our system of supporting these individuals is successful, since the events are not common. Another interpretation is that almost all of these events should be preventable, given enough interest and engagement in the problem. In this registry, there were no gradations for amount of dementia or psychiatric illness, but only general diagnosis categories. For individuals with minimal functional impairment, they often still maintain their own private living situation, where they may even live alone. For those with more severe functional impairment, they likely have steady supervision. Many of the alarm systems, for those that have chosen to have a simplified alarm at home, where they can call for help by, for example, pressing an alarm button, rely on the individual to have their alarm button in close proximity, and optimally with them at all times, with some form of radio signalling. More and more, sensors are being incorporated or linked to communication devices, such as mobile telephones. It should be possible, in the near future, to link (among other things) a thermometer on something that the individual wears, and when decreasing temperature is noted, a pre-programed telephone signal could be sent out automatically, not requiring the individual to actively and consciously 
initiate an alarm. This type of simple monitoring and signalling should be applicable to high risk individuals. In general, we associate an obligatory bracelet with some form of limitation in autonomy (such as a prisoner's location bracelet). In this case, both sensors and alarms now come in the form of bracelets and watches, and mobile telephones and mobile telephone signal coverage is almost ubiquitous, at least in areas where there are roads and homes.

There have been no obvious pre-morbid indicators which might favour survival when exposed to hypothermia, at least from these observations. It may be that those who survived and those who died are essentially a similar group of individuals, and that the survivors where just fortunate enough to be found early in the process. It was unexpected (for me, at least) that so many of the fatal hypothermia victims were found so near to houses and other people, including in rural settings. My reflection is that many of these deaths should have been preventable. There has been a clear association between fatal hypothermia in cities and acute intoxication (Tanaka and Tokudome 1990). Acute intoxication and cold climate have been described by a learned source in our hospital/university as a malignant combination.

The data collection in Paper II was strengthened by the complete and systematic post-mortem examination reports. The associated police and hospital/physician documentation was much less complete. It is clearly possible to succumb to hypothermia even in the warmer months in the Nordic climate, but to not document the local conditions surrounding a suspected hypothermic death may be a result of that the report writer does not consider that there may be a link between environmental conditions and the process of hypothermia. This could be improved by relatively simple educational initiatives, and to stimulate interest in the causes of hypothermic death that are not behaviour or medical conditions.

Pancreatitis seems to have crept into the literature about hypothermia based on two different processes. First, there was an early published series of hypothermia victim hospital admissions, where the victims survived initially, lingered for a time, but then met their demise in a stormy syndrome of pancreatitis and multiple organ dysfunctions (Foulis 1982). The other process may be the abundant literature about cardiopulmonary bypass with hypothermia and resultant hyperamylasemia (Collins and Danzl 2006; Stiff et al. 2003; Ihaya et al. 2001). There has been speculation that the cold injury directly will lead to autophagy in the pancreas, and that some degree of pancreas autodigestion should be expected if the cause of death was hypothermia. In the post-mortem examinations in Paper II, pancreatitis was quite infrequent. It is not unusual that anecdotal reporting can lead to wide generalization, and it may be that these early anecdotes have been repeated often enough (in review articles, for example) that they become common belief.

In Papers III and IV, the phenomena studied in the cold hand provocation model included local and central regulation, as well as local effector organ function. There is a strong response in the peripheral microvasculature to cold insult, known 
as cold-induced vasoconstriction (Cheung and Daanen 2011). During cold exposure, there is increased vascular tone, in part due to increased sympathetic nervous system output along with normal vasoconstrictive response to this neurogenic input. This central signal for peripheral vasoconstriction relies on intact central regulation and function, which diminishes eventually during progressive decrease of core body temperature. It relies also on intact vascular smooth muscle function, which also at some point in cooling, diminishes. During progressing cooling, there is initially vasoconstriction, but then there also are waves of intermittent and relative brief relief from this vasoconstriction. This can be seen as a reflex which is known as cold induced vasodilation (CIVD) or 'Hunting' response (Lewis 1930), which functionally results in better use of the extremities for a brief time. Cold-induced vasoconstriction and vasodilation, then, comes in waves, with some short periods of relief, all of this centrally neurologically mediated. There seems to be a large amount of individual variation in how this cold-induced vasoconstriction and vasodilation pattern occurs. (Cheung and Daanen 2011; Flouris 2008) The studies in my thesis have examined the initial steps of extremity cooling/rewarming, where core temperature is normal. This cold-induced vasodilation typically occurs with more prolonged cooling than what was incorporated into my model (10 minutes). These complex aspects of autonomic nervous system regulation and function are central concerning an individual's response to cold and the process of cold injury.

Once there is cooling to the extent that the central regulation and peripheral effector aspects governing microcirculation become impaired, then there can be a phase of vasoplegia locally, leading to a last phase of perfusion of a cold extremity, before the central circulation also becomes diminished. This may be a possible explanation for a stimulus that is part of 'paradoxical undressing' that was described in Paper II. This type of event may produce a phase with discomfort, that a victim may try to alleviate by removing clothing.

Central to Papers III and IV was a 15-month interval of cold climate training in the volunteer subjects. While the studies showed that there were signs of changed rewarming responses as well as autonomic nervous system output pattern after cold training, the clinical significance of these findings are unclear. For example, all the subjects (soldiers) most likely had better general physical condition and possibly a more robust resting circulation, all acquired through daily rigorous physical training. It is impossible to separate the effects of cold training and general physical cardio-pulmonary and vascular training on the expression of the autonomic nervous system. The hand cooling and rewarming measurements are likely more specific for cold training. In order to separate the effects of general physical conditioning and cold exposure, we would need to do another study involving cold exposure in individuals that abstained from general physical conditioning. 
Concerning adaptation to cold, and how much of cold tolerance is related to genotype, one can reflect on the situation of arctic indigenous peoples, and also non-arctic peoples who work in cold climate, such as fishermen. When examining incidence of frostbite, it seems that reindeer herder and seafaring workers in cold climates have a relatively high and similar incidence of frostbite. (Hassi and Mäkinen 2000) It is not easy to compare cold exposure, and it is possible that one group here tolerates much more cold than the other. That both these groups have high incidences of frostbite speaks mostly about extreme exposure, since both groups are generally experienced with, and prepared for cold. One theory about cold tolerance is that there is little adaptation to cold, but rather that those with low cold tolerance generally leave the colder regions for something that for them is more comfortable. This argues for a strong genotype relation to cold tolerance, and that the phenotype is little changed by cold exposure. If there has been a collection of more cold tolerant genes within, for example, indigenous peoples in cold regions, then it would be of interest to try to demonstrate this in terms of autonomic nervous system responses compared to a matched non-arctic group.

Even if there was some degree of cold adaptation, it is not clear if this would lead to a meaningful reduction in cold injuries. For those where there is not significant chronic medical illness, probably the most important factor in preventing cold injury is the individual's judgment concerning how much cold exposure they can tolerate without sustaining an injury. A miscalculation for one that works in a cold climate can quickly result in injury. Sometimes there are accidents, injuries, or unforeseen events that impair an individual's ability to prevent exposure. For those with experience and a clear respect for the potential for cold injury, then their preparedness and effectiveness in preventing exposure may be what prevents injury. Still, if one cannot completely control the degree of exposure to cold, then a meaningful amount of cold-training and additional cold tolerance could be the difference between survival and non-survival.

If there was a simple means to test for cold-tolerance (or relative coldintolerance), then for an employer in a cold region, or where the work is conducted in cold environments, might see a benefit to get some insight into a prospective employees cold tolerance. Still, probably the most important factor for success for an employee in a cold environment is the mental/psychological aspects related to both their job and their work environment. Cold-tolerance and cold-trainability probably would have a relatively small impact in this setting. But for a motivated employee, who had some difficulty with cold tolerance, then controlled cold exposure with the hopes of increasing cold tolerance, together with encouragement of optimal general physical condition and removal of factors which impair cold tolerance could improve both work function and employee health. 


\section{Methodological considerations}

For Paper I, it would have been optimal if there was absolute consistency in the data gathering process. There were several research nurses, but it was not possible for me to oversee and double-check all the collected data. One way that we tried to ensure optimal data collection was to have a careful introduction with the individual research nurses. A second way was that I performed spot checks on the collected data. I examined all outlier values directly. This type of retrospective assessment still could only be as good as the hospital journal records upon which it was based. In order to have more complete results for this type of cohort, then prospective and more structured data input would be necessary. If a data collection form, which was prospectively designed to both guide therapy and facilitate data collection, was made available to all physicians in our region that treated cold injury patients, then I would expect both more complete documentation and better regional data collection. Still, this retrospective collection and analysis provided much useful data. For Paper II, there are similar considerations for the retrospective nature of the data collection. For this type of formal registry, it should be possible to examine records for these diagnoses for the whole country, though I chose to start with my region. In part, this was a matter of feasibility with the resources available for my research and research education activities. There remains a question if the results from the northern region represent what has occurred in all of Sweden, though there is no obvious reason to doubt that it does.

For Papers III and IV, there are some clear methodological limitations as far as generalizability of the results to the population in general. The first is that all the subject were healthy young men (no women), and that they also probably did not represent the general population both health/illness-wise and also in some aspects of their behaviour and physiology. Another limitation in the study design is that it is not easy to quantify cold exposure. There was without any doubt lots of cold exposure and it was similar for all in the cohort, but still, it is difficult to quantify. Another limitation is the risk for under-reporting of cold injuries. Soldiers are known to both under- and over-report injuries and illnesses, depending on how it affects their duty plans. This was an exclusive and highly motivated 'special forces' army group, where soldiers may not spontaneously report minor injuries that occurred due to lack of caution or not following instructions, if they thought that this might affect their opportunity to continue with the group. Also, the fact that these subjects thought about their active participation in a cold-training and 'cold injury' study may have modified their behaviour, possibly leading them to take fewer chances with cold exposure. This might have been most relevant for the officers and the orders given to the soldiers, since they knew that they could be subject to extra scrutiny and review. 


\section{CONCLUSIONS}

Hypothermia and local cold injury continue to be common forms of accidental injury and hospitalization in the northern region of Sweden.

Assessment of hypothermia, and hence management, does not appear to be standardized across hospitals.

Local cold injury continues to lead to hospitalizations and disability.

More standardized patient assessment, management, and documentation are needed in order to be able to decrease risk for these events, and improve patient care when they occur.

With the identification of groups at high risk for fatal hypothermia, it should be possible to reduce risk through thoughtful interventions, particularly related to the highest risks: rural, living alone, alcohol-over consumption, and psychiatric diagnosis-carrying subjects.

Slower rewarming function, as demonstrated in the cold recovery test, may be related to the occurrence of local cold injury during long-term cold-weather training.

Cold training appears to improve cold recovery and rewarming, at least concerning the hands of healthy individuals, and to a relatively larger extent in individuals who have slower rewarming.

Adaptation to prolonged cold exposure occurs in the autonomic nervous system as shown by heart rate variability, as far as response to cold provocation in hands.

Further prospective study is needed to determine if cold adaptation provides significant protection to subjects at higher risk for cold injury. 


\section{FUTURE PERSPECTIVES}

While it is a good starting point to have mapped out how our health care organisations diagnose, treat, and manage patients with cold injuries, the main focus must be to try to do better. In our health care setting, we steadily try to use our resources rationally. There must be a good reason for new investment. In general, we try to treat specific diagnosis groups with a clearly identified and approved treatment plan. My hope with these studies is that more ideas come forward about how to identify, treat, and plan for patients with cold injury. Clearly, prospective studies are needed in this field. Only few studies have focused on temperature kinetics in hypothermia victims (how rewarming and temperature distribution actually occurs). Data on pharmacokinetics and pharmacodynamics of resuscitation drugs at different core body temperatures are sparse. These are not simple conditions to study.

Also, I think that study of the physiology related to adaptation to cold environments should be expanded to try to better understand the degree of adaptation that can occur in different cohorts or phenotypes, and who can benefit the most. It may be that this type of adaptation is also beneficial for other patient groups, where less sympathetic nervous system output is desirable. This is possibly relevant for most adults, even without illness, but it might be particularly relevant for patients with ischemic heart disease and hypertension. 


\section{ACKNOWLEDGEMENTS}

I want to express my gratitude and appreciation to my colleagues and the staff of the Department of Anesthesia and Intensive Care Medicine, the Emergency and Disaster Medical Centre, and to the administrative leadership of the Västerbotten County Council, all of whom have helped to make this work possible.

I want to thank my supervisors, over many years Kalle Ängquist, who has helped me get into the final phase, to Michael Haney, my main supervisor, for his skillful and never-ending positive support, and also to my excellent co-supervisors Urban Wiklund, Anders Eriksson, and Ola Winsö. Göran Johansson has provided very necessary support. I also want to thank Björn Biber, who inspired and supported me in the start of my hypothermia research project.

I give my gratitude and thanks to Gordon Giesbrecht, an extraordinary hypothermia researcher and expert, who has helped and supported me from near and far, both in Canada and in Sweden over many years.

Also, I have much gratitude for my long-time mentors and friends, hypothermia experts Bruce Paton and Murray Hamlet, who have inspired my interest in these subjects and have participated in a many-year teaching collaboration.

Gratitude goes to WJ Mills (now deceased) and Dan Danzl, who opened their homes and shared so much of their expertise with me.

I am very grateful for excellent and pleasant collaboration in these projects with Helena Grip, Marcus Karlsson, Per Hallberg, and Christer Grönlund.

Thanks to my research collaborators who have helped me collect and collate results from different hospitals in our regions: Lena Algers, Monica Palmén, Victoria Popovac-Lindström, Erika Bäckström-Löfquist, Marit Sarri, Marie Nordgren, Lena Nilsson, Marianne Ekström, and Annika Kumlin.

I want to thank my colleagues Per-Åke Nilsson, Susannah Sigurdsson, and Åsa Ljungquist, at the National Board of Health and Welfare, in the section for Disaster Preparedness, who have helped promote the national educational program on cold injuries.

My gratitude and appreciation goes to Tony Gustafsson at the Swedish Army's Special Forces regiment in Arvidsjaur, for many years of friendship and collaboration in training different groups of volunteers in cold environments. 
To my mentor and friend Sven-Erik Åkerlind, who taught me how to say what needs to be said in 30 seconds, and spend the rest of the time to discuss why I said it.

I want to thank to my brothers and sisters who are always there.

My sincere thanks to Anna-Lena, Helena, Johan and Eva who are not the least competitive but count every second and kilometer running, skiing and cycling and promise to keep me young. 


\section{Populärvetenskaplig sammanfattning på svenska}

Accidentell hypotermi, oplanerad sänkning av kroppens kärntemperatur till under 35 grader $\mathrm{C}$, är ett hot mot såväl vår hälsa som livet. Förfrysningsskador, framförallt av händer och fötter, kan leda till amputationer och livslånga men. Vi har undersökt omfattningen av accidentell hypotermi och förfrysningsskador i norra Sverige under de senaste åren, både for de som har frusit ihjäl och de som har överlevt och fått vård på sjukhus. Vi har också undersökt om det finns ett samband mellan förmågan att värma upp sina händer efter att ha utsatts för kyla och risken för förfrysningsskador. I studierna som ingår i avhandlingen har vi funnit att det är en väsentlig omfattning av både accidentell hypotermi och förfrysningsskador, både sådana som leder till vård på sjukhus, men också sådana som leder till amputation och dödsfall. Vi har också kunnat visa att det finns ett samband mellan förmågan att värma upp händerna efter en kylaprovakation och förekomsten av

förfrysningsskador. Studierna visar även att lång tids vistelse i kallt klimat kan positivt förbättra hjärt- och kärlreflexer och cirkulation hos friska frivilliga. Allt sammantaget, finns det skäl att fortsätta att utveckla behandlingen av patienter som drabbas av kylskador. Det finns också anledning att tro att man kan anpassa sig till kallt klimat, men om det innebär att man kan minska risken för kylskador när man blir utsatt för en kraftig kylaexponering är fortfarande oklart. 


\section{REFERENCES}

Ahle NW, Buroni JR, Sharp MW, Hamlet MP. Infrared thermographic measurement of circulatory compromise in trenchfoot-injured argentine soldiers. Aviat Space Environ Med. 1990; 61: 247-50.

Albiin N and Eriksson A. Fatal accidental hypothermia and alcohol. Alcohol Alcoholism. 1984; 19: 13-22.

Alfonzo A, Lomas A, Drummond I, McGugan E. Survival after 5-h resuscitation attempt for hypothermic cardiac arrest using CVVH for extracorporeal rewarming. Nephrol Dial Transplant. 2009; 24(3): 1054-6.

Anburajan M, Sivanandam S, Bidyarasmi S, Venkatraman B, Menaka M, Raj B. Changes of skin temperature of parts of the body and serum asymmetric dimethylarginine (ADMA) in type-2 diabetes mellitus Indian patients. Conf Proc IEEE Eng Med Biol Soc. 2011; (): 6254-9.

Althaus U, Aeberhard P, Schüpbach P, Nachbur BH, Mühlemann W. Management of profound accidental hypothermia with cardiorespiratory arrest. Ann Surg. 1982; 195(4): 492-5.

Ariev TJ. Monograph on frostbite. Narkomzdrav, USSR, State Health Committee: 1940. (Translated by Defence Research Board, Canada, 1955).

Ashworth M, Arthur M, Pye G, Loehry CA. Missed injuries of the spinal cord. Br Med J (Clin Res Ed). 1982; 284(6325): 1334-5.

Aslam AF, Aslam AK, Vasavada BC, Khan IA. Hypothermia: evaluation, electrocardiographic manifestations, and management. Am J Med. 2006; 119(4): 297 301.

Astrup J et al. Increase in extracellular potassium in the brain during circulatory arrest: effects of hypothermia, lidocaine, and thiopental. Anesthesiology. 1981; 55(3): 256-62.

Auerbach PS. Some people are dead when they're cold and dead. JAMA. 1990; 264(14): 1856-7.

Bangs CC and Hamlet MP Hypothermia and cold injuries. In Auerbach P. Geehr E, editors: Management of wilderness and environmental emergencies. Macmillan; New York, 1983

Bangs CC. Hypothermia and frostbite. Emerg Med Clin North Am. 1984; 2: 475-87.

Baraka A. Hydrogen ion regulation during hypothermia: hibernators versus ectotherms. Middle East J Anesthesiol. 1984; 7(4): 235-8.

Baraka AS, Baroody MA, Haroun ST, Sibai AA, Nawfal MF, Dabbous AS, Taha SK, elKhatib RA. Effect of alpha-stat versus pH-stat strategy on oxyhemoglobin dissociation and whole-body oxygen consumption during hypothermic cardiopulmonary bypass. Anesth Analg. 1992; 74(1): 32-7.

Bergersen TK, Hisdal J, Walløe L. Perfusion of the human finger during cold-induced vasodilatation. Am J Physiol. 1999; 276(3 Pt 2): R731-7.

Bernard S. Hypothermia after cardiac arrest: expanding the therapeutic scope. Crit Care Med. 2009; (7 Suppl): S227-33.

Bettley FR, Eczema in children. Excerpta Med (Dermatol). 1957; 11(3): 99-100. 
Bjornstad H, Tande PM, Refsum H. Cardiac electrophysiology during hypothermia: implications for medical treatment. Arctic Med Res. 1991; 50: 71-5.

Blair E. Physiology of hypothermia. In Clinical Hypothermia. McGraw-Hill: New York, 1964.

Boelhouwder RU, Bruining HA, Ong GL. Corrections of serum potassium fluctuations with body temperature after major surgery. Crit Care Med. 1987;15(4):310-2.

Boswick JA Jr, Thompson JD, Jonas RA. The epidemiology of cold injuries. Surg Gynecol Obstet. 1979; 149(3): 326-32.

Boutelier C. Survival and protection of aircrew in the event of accidental immersion in cold water. NATO 1979 AGARD Report No AG-211, Neuilly Sur Seine, France.

Brown GM, Semple RE, Lennox CS, Bird GS, Baught CW. Response to cold of Eskimos of the Canadian Arctic. J Appl Physiol 1963; 18, 970-74.

Bruen KJ, Ballard JR, Morris SE, Cochran A, Edelman LS, Saffle JR. Reduction of the incidence of amputation in frostbite injury with thrombolytic therapy. Arch Surg. 2007; 142(6): 546-51.

Bräuer A, Wrigge H, Kersten J, Rathgeber J, Weyland W, Burchardi H. Severe accidental hypothermia: rewarming strategy using a veno-venous bypass system and a convective air warmer. Intensive Care Med. 1999; 25(5): 520-3.

CDC. Hypothermia-related mortality Montana 1999-2004. MMWR Morb Mortal Wkly Rep. 2007 20; 56(15): 367-8.

Cauchy E, Chetaille E, Marchand V, Marsigny B. Retrospective study of 70 cases of severe frostbite lesions: a proposed new classification scheme. Wilderness Environ Med. 2001; 12(4): 248-55.

Chandran GJ, Chung B, Lalonde J, Lalonde DH. The hyperthermic effect of a distal volar forearm nerve block: a possible treatment of acute digital frostbite injuries? Plast Reconstr Surg. 2010; 126(3): 946-50.

Chang M and Gill T. Hypothermia. neurological dysfunction, and sudden death in a man with carcinoma. South Med J. 1981; 74: 1509.

Cheung SS and Daanen HA. Dynamic adaptation of the peripheral circulation to cold exposure. Microcirculation 2012; 19(1): 65-77.

Clements SD and Hurst JW. Diagnostic value of electrocardiographic abnormalities observed in subjects accidentally exposed to cold. Am J Cardiol. 1972; 29: 729-34.

Cleophas TJ, Fennis JF, van't Laar A. Finger temperature after a finger-cooling test: Influence of air temperature and smoking. J Appl Physiol $1982 ; 52: 1167-71$.

Collins AM, Danzl DF. Hypothermia with profound anemia and pancreatitis. Wilderness Environ Med. 2006; 17(1): 31-5.

Covino BG and Beavers WR. Changes in cardiac contractility during immersion hypothermia. Am J Physiol. 1958; 195: 433-6.

Daanen HA. Finger cold-induced vasodilation: a review. Eur J Appl Physiol. 2003; 89(5): 411-26.

Danielsson U. Wind chill and the risk of tissue freezing. J Appl Physiol. 1996; 81(6): 266673. 
Danzl DF, Pozos RS, Auerbach PS, Glazer S, Goetz W, Johnson E, Jui J, Lilja P, Marx JA, Miller J. Multicenter hypothermia survey. Ann Emerg Med. 1987; 16(9): 1042-55.

Danzl DF. Accidental hypothermia. In Rosen et al. (editors): Emergency Medicine: Concepts and Clinical Practice, 2nd ed. Mosby: St Louis; 1988.

Danzl DF, Pozo RS, Hamlet MP. Accidental hypothermia. In Auerbach PS, Geehr EC (editors): Management of wilderness and environmental emergencies, 3rd ed., Mosby: St Louis; 1998.

Danzl D, Pozos RS, Hamlet MP. Accidental hypothermia. In: Auerbach PS, ed. Wilderness Medicine:Management of Wilderness and Environmental Emergencies. 3rd ed. St Louis, Mo: Mosby-Year Book, Inc; 1995: 55.

Davies DM, Millar EJ, Miller IA. Accidental hypothermia treated by extracorporeal bloodwarming. Lancet. 1967; 1(7498): 1036-7.

Deakin CD. Forced air surface rewarming in patients with severe accidental hypothermia. Resuscitation. 2000; 43(3): 223.

Deakin CD, Nolan JP, Soar J, Sunde K, Koster RW, Smith GB, Perkins GD. European Resuscitation Council Guidelines for Resuscitation 2010 Section 4. Adult advanced life support. Resuscitation 2010; 81(10): 1305-52.

De Witte J, Sessler DI. Perioperative shivering: physiology and pharmacology. Anesthesiology. 2002; 96(2): 467-84.

Duguid H, Simpson RG, Stowers JM. Accidental hypothermia. Lancet. 1961; 2(7214): 1213-9.

Dupuis H. Thermographic assessment of skin temperature during a cold provocation test . Scand J Work Environ Health. 1987; 13: 352-5.

Durrer B, Brugger H, Syme D. The medical on-site treatment of hypothermia: ICARMEDCOM recommendation.International Commission for Mountain Emergency Medicine. High Alt Med Biol. 2003; 4(1): 99-103.

Ehrmantraut WR, Ticktin HE, Fazekas JF. Cerebral hemodynamics and metabolism in accidental hypothermia. Arch Intern Med. 1957; 99: 57-9.

Edwards HA, Benstead JG, Brown K, Makary AZ, Menon NK. Apparent death with accidental hypothermia. A case report. Br J Anaesth. 1970; 42(10): 906-8.

Fallis WM. Monitoring temperature in trauma patients: New research and new technologies. J Emerg Nurs. 2002; 28(5): 471-2.

Ferguson NV. Urban hypothermia. Anesthesia. 1985; 40: 651-4.

Ferrara A, MacArthur JD, Wright HK, Modlin IM, McMillen MA. Hypothermia and acidosis worsens coagulopathy in the patient requiring massive transfusion. Am J Surg 160:515-8, 1990.

Ferraro FJ Jr, Spillert CR, Swan KG, Lazaro EJ. Cold-induced hypocoagulability in vitro, a trauma connection? Am Surg 1992; 58: 355-7.

Finderle Z, Cankar K. Delayed treatment of frostbite injury with hyperbaric oxygen therapy: a case report. Aviat Space Environ Med. 2002; 73(4): 392-4.

FitzGibbon FT, Hayward JS, Walker D. EEG and visual evoked potentials of conscious man during moderate hypothermia. Electroenceph Clin Neurophysiol. 1984; 58: 48. 
Flouris AD, Westwood DA, Mekjavic IB, Cheung SS. Effect of body temperature on cold induced vasodilation. Eur J Appl Physiol 2008; 104(3): 491-9.

Flouris AD and Cheung SS. On the origins of cold-induced vasodilation. Eur J Appl Physiol. 2010; 108(6): 1281-2.

Fox RH, Davies TW, Marsh FP, Urich H. Hypothermia in a young man with an anterior hypothalamic lesion. Lancet. 1970; 2(7665): 185-8.

Fowler R, Gallagher JV, Isaacs SM, Ossman E, Pepe P, Wayne M. The role of intraosseous vascular access in the out-of-hospital environment (resource document to NAEMSP position statement). Prehosp Emerg Care. 2007; 11(1): 63-6.

Francis TJ and Golden FS. Non-freezing cold injury: the pathogenesis. J R Nav Med Serv. 1985; 71(1): 3-8.

Froese G and Burton AC. Heat loss from the human head. J Appl Physiol. 1957; 10: 235.

Fuhrman FA and Crismon JM. Studies on gangrene following cold injury. VII. Treatment of cold injury by means of immediate rapid rewarming. J Clin Invest. 1947; 26: 476-85,

Fulbrook P. (a) Core temperature measurement: a comparison of rectal, axillary and pulmonary artery blood temperature. Intensive Crit Care Nurs. 1993; 9(4): 217-25.

Fulbrook P. J. (b) Core temperature measurement in adults: a literature review. Adv Nurs. 1993; 18(9): 1451-60.

Gentilello LM, Cobean RA, Offner PJ, Soderberg RW, Jurkovich GJ. Continuous arteriovenous rewarming: rapid reversal of hypothermia in critically ill patients. $J$ Trauma. 1992; 32(3): 316-25.

Giesbrecht GG and Bristow GK. A second post-cooling afterdrop: more evidence for a convective mechanism. J Appl Physiol. 1992; 73(4): 1253-8.

Gilbert M, Busund R, Skagseth A, Nilsen PA, Solbø JP. Resuscitation from accidental hypothermia of 13.7 degrees $C$ with circulatory arrest. Lancet. 2000; 355: 375-6.

Gildenberg PL, Hardenbergh E. The effect of immediate sympathectomy on tissue survival following experimental frostbite. Ann Surg. 1964; 160: 160-8.

Greene R. Cold in the treatment of damage due to cold. Lancet 1942; 695.

Golden FStC, Hervey GR. The mechanism of the after-drop following immersion hypothermia in pigs. J Physiol. 1977; 272: 26-27.

Goldman A, Exton-Smith AN, Francis G, O'Brien A. A pilot study of low body temperature in old people admitted to hospital. J R Coll Phys Lond. 1977; 11(3): 291-306.

Gregory RT, Patton JF 3rd, Whitby JD, Berkeley JS, Hillman H. Treatment after exposure to cold. Lancet. 1972; 1(7746): 377-8.

Gregory JS, Bergstein JM, Aprahamian C, Wittmann DH, Quebbeman EJ. Comparison of three methods of rewarming from hypothermia; advances of extracorporeal blood rewarming. J Trauma. 1991; 31(9): 1247-51. discussion 1251-2.

Grieve AW, Davis P, Dhillon S, Richards P, Hillebrandt D, Imray CH. A clinical review of the management of frostbite. J R Army Med Corps. 2011; 157(1): 73-8.

Guerin JM, Meyer P, Segrestaa JM. Hypothermia in diabetic ketoacidosis. Diabetes Care 1987; 10: 801 . 
Greenfield AD, Kernohan GA, Marshall RJ, Shepherd JT, Whelan RF. Heat loss from toes and fore-feet during immersion in cold water. J Appl Physiol. 1951; 4(1): 37-45.

Hall JE, ed- Textbook of Medical Physiology. $11^{\text {th }}$ edition; Elsevier/Saunders: New York; 2006.

Hallam MJ, Cubison T, Dheansa B, Imray C. Managing frostbite. BMJ. 2010; 341: c5864.

Hardenbergh E, Ramsbottom R. Experimental frostbite. The effect of "double freeze" on tissue survival in the mouse foot. Cryobiology. 1969; 5(5): 336-9.

Harnett RM, O'Brien EM, Sias FR, Pruitt JR. Initial treatment of profound accidental hypothermia. Aviat Space Environ Med 1980; 51: 680-7.

Harnett RM, Pruitt JR, Sias FR. (a) A review of the literature concerning resuscitation from hypothermia. I. The problem and general approaches. Aviat Space Environ Med 1983; 54: 425-34.

Harnett RM, Pruitt JR, Sias FR. (b) A review of the literature concerning resuscitation from hypothermia. II. Selected rewarming protocols. Aviat Space Environ Med 1983; 54:487-95.

Hassi J, Mäkinen TM. Frostbite: occurrence, risk factors and consequences. Int J Circumpolar Health. 2000; 59(2): 92-8.

Hashmi MA, Rashid M, Haleem A, Bokhari SA, Hussain T. Frostbite: epidemiology at high altitude in the Karakoram mountains. Ann R Coll Surg Engl. 1998; 80(2): 91-5.

Hayward JS, Eckerson JD, Collis ML. Thermal balance and survival time prediction of man in cold water. Can J Physiol Pharmacol. 1975; 53: 21. (a).

Hayward JS and Steinman AM. Accidental hypothermia: an experimental study of inhalation rewarming. Aviat Space Environ Med 1975; 46: 1236-40. (b)

Heggers JP, Robson MC, Manavalen K, Weingarten MD, Carethers JM, Boertman JA, Smith DJ Jr, Sachs RJ. Experimental and clinical observations on frostbite. Ann Emerg Med 1987; 16(9): 1056-62.

Henriksson O, Lundgren JP, Kuklane K, Holmér I, Bjornstig U. Protection against cold in prehospital care-thermal insulation properties of blankets and rescue bags in different wind conditions. Prehosp Disaster Med. 2009; 24(5): 408-15.

Henriques FC, Moritz AR. Studies of Thermal Injury: I. The Conduction of Heat to and through Skin and the Temperatures Attained Therein. A Theoretical and an Experimental Investigation. Am J Pathol. 1947; 23(4): 530-49.

Himms-Hagen J. Thermogenesis in brown adipose tissue as an energy buffer. N Engl J Med 1984; 311: 1549.

Hirvonen J and Huttunen P. Necropsy findings in fatal hypothermia cases. Forensic Sci 1976; 8: 155.

Hoskin RW, Melinyshyn MJ, Romet TT, Goode RC. Bath rewarming from immersion hypothermia. J Appl Physiol. 1986; 61(4): 1518-22. Erratum in J Appl Physiol 1986 Dec;61(6): following 2314.

Hughes A, Riou P, Day C ,Full neurological recovery from profound $\left(18.0^{\circ} \mathrm{C}\right)$ acute accidental hypothermia: successful resuscitation using active invasive rewarming techniques. Emerg Med J. 2007; 24(7): 511-512. 
Ihaya A, Muraoka R, Chiba Y, Kimura T, Uesaka T, Morioka K, Matsuyama K, Tsuda T, Nara M, Niwa H. Hyperamylasemia and subclinical pancreatitis after cardiac surgery. World J Surg. 2001; 25(7): 862-4

Ikäheimo TM, Hassi J. Frostbites in circumpolar areas. Glob Health Action. 2011;4. doi: 10.3402/gha.v4i0.8456.

Iyengar J \& Bhakoo ON. Prevention of neonatal hypothermia in Himalayan village: role of domiciliary caretaker. Trop Geogr Med. 1991; 43: 293-6.

Johnston CE, Bristow GK, Elias DA, Giesbrecht GG. Alcohol lowers the vasoconstriction threshold in humans without affecting core cooling rate during mild exposure. Eur J Appl Physiol. 1996; 74: 293-5.

Jonsson DE and Gamble WB. Trauma in the arctic: an incident report. J Trauma.1991;31: 1340.

Jolly BT, Ghezzi KT. Accidental hypothermia. Emerg Med Clin North Am. 1992; 10(2): 311-27.

Jurkovich GJ Greiser WB, Luterman A, Curreri PW. Hypothermia in trauma victims: an ominous predictor of survival. J Trauma 1987; 27: 1019.

Jurkovich GJ. Environmental cold-induced injury. Surg Clin North Am 2007; 87(1): 24767 viii.

Kattlove HE and Alexander B. The effect of cold on platelets. I. Cold-induced platelet aggregation. Blood. 1971; 38(1): 39-48.

Kattlove HE, Alexander B, White F. The effect of cold on platelets. II. Platelet function after short-term storage at cold temperatures. Blood. 1972; 40(5): 688-96.

Koht A, Cane R, Cerullo LJ. Serum potassium levels during prolonged hypothermia. Intensive Care Med. 1983; 9(5): 275-7.

Kondratiev TV, Wold RM, Aasum E, Tveita T. Myocardial mechanical dysfunction and calcium overload following rewarming from experimental hypothermia in vivo, Cryobiology. 56(1):15-21, 2008.

Keatinge WR. Survival in cold water. Blackwell Scientific: Oxford: 1969.

Kempainen RR and Brunette DD. The evaluation and management of accidental hypothermia. Respir Care. 2004; 49(2): 192-205.

Kornberger E, Schwarz B, Lindner KH, Mair P. Forced air surface rewarming in patients with severe accidental hypothermia. Resuscitation. 1999; 41(2): 105-11.

Krakauer J. Into Thin Air: a personal account of the Mount Everest disaster. Villard, New York, 1997.

Krog J, Folkow B, Fox RH, Andersen KL. Hand circulation in the cold of Laps and north Norwegian fishermen. J Appl Physiol. 1960; 15: 654-8.

Krook G. Hypothermia in patients with exfoliative dermatitis. Acta Derm Venereol. 1960; 40: $142-60$.

Larrey DJ (Baron). Surgical memoirs of the campaigns of Russia, Germany and France. Translated from French by J.C. Mercer. Philadelphia. Lea and Carey 1832: p72. 
Lamke LO, Liljedahl SO, Lennquist S. The influence of cold stress on cathecholamine excretion and oxygen uptake in normal persons. Scand J Clin Lab Invest. 1972; 30: 5762.

Lefrant JY, Muller L, de La Coussaye JE, Benbabaali M, Lebris C, Zeitoun N, Mari C, Saïssi G, Ripart J, Eledjam JJ. Temperature measurement in intensive care patients: comparison of urinary bladder, oesophageal, rectal, axillary, and inguinal methods versus pulmonary artery core method. Intensive Care Med. 2003; 29(3): 414-8.

Lennquist S. Sodium reabsorption in cold diuresis. Swedish Defence Med. 1971; 7: 108.

Lennquist S. Cold-induced diuresis, a study with special reference to electrolyte excretion, osmolal balance and hormonal changes. Scand J Urol and Nephrol. 1972; Suppl 9, 1142.

Lennquist S, Granberg P-O, Wedin B. Fluid balance and physical work capacity in humans exposed to cold. Arch Environ Health. 1974; 29: 241-9.

Lewin S, Brettman LR, Holzman RS. Infections in hypothermic patients. Arch Intern Med. 1981; 141(7): 920-5.

Lewis T. Observations upon the reactions of the vessels of the human skin to cold. Heart. 1930; 15: 177-208.

Livingston JH and Groggings RC. Clinical curio: hypothermia caused by treatment of a scald. Br Med J. 1984; 228: 771.

Lloyd EL. Accidental hypothermia treated by central rewarming through the airway. Br J Anaesth. 1973; 45(1): 41-8.

Lloyd EL and Mitchell B. Factors affecting the onset of ventricular fibrillation in hypothermia. Lancet 1974; 2: 1294-6.

Lloyd EL. Accidental hypothermia.Resuscitation. 1996; 32(2): 111-24.

Lundgren JP, Henriksson O, Pretorius T, Cahill F, Bristow G, Chochinov A, Pretorius A, Bjornstig U, Giesbrecht GG. Field torso-warming modalities: a comparative study using a human model. Prehosp Emerg Care. 2009; 13(3): 371-8.

Lundgren $\mathrm{P}$, Henriksson $\mathrm{O}$, Naredi $\mathrm{P}$, Björnstig U. The effect of active warming in prehospital trauma care during road and air ambulance transportation - a clinical randomized trial. Scand J Trauma Resusc Emerg Med. 2011; 19: 59.

Mackowiak PA, Wasserman SS, Levine MM. A critical appraisal of $98.6^{\circ} \mathrm{F}$, the upper limit of the normal body temperature, and other legacies of Carl Reinhold August Wunderlich. JAMA 1992; 268: 1578.

McCauley RL, Heggers JP, Robson MC. Frostbite. Methods to minimize tissue loss. Postgrad Med. 1990; 88(8): 67-8.

Maclean D and Emslie-Smith D. Accidental hypothermia, Philadelphia: JB Lippincott; 1977.

Maclean D, Murison J, Griffiths PD. Acute pancreatitis and diabetic ketoacidosis in accidental hypothermia and hypothermic myxoedema. Br Med J. 1973; 4(5895): 75761.

MacLean D, Murison J, Griffiths PD. Acute pancreatitis and diabetic ketoacidosis in hypothermia. Br Med J. 1974; 2(5909): 58-9. 
Mathew L, Purkayastha SS, Nayar HS. Variation in the susceptibility to cold injury in Indians. Int J Biometeorol. 1979; 23(3): 263-70.

Meehan JP. Racial and individual differences in the peripheral vascular response to a cold stimulus. Am J Physiol. 1954; 179: 547-661.

Meehan JP. Body Heat production and surface temperatures in response to a cold stimulus. J Physiol. 1955; 7:537-41.

Menard MR and Hahn G. Acute and chronic hypothermia in a man with spinal cord injury: environmental and pharmacological causes. Arch Phys Med Rehabil 1991; 74: 421.

Michenfelder JD and Milde JH. The relationship among canine brain temperature,metabolism, and function during hypothermia. Anesthesiology 1991; 75: 130.

Miller LK and Irving L, Local reactions to air cooling in an Eskimo population. J Appl Physiol. 1962; 17: 449-55.

Mills WJ, Whaley R, Fish W. Frostbite, I: Experience with rapid rewarming and ultrasonic therapy. Alaska Med. 1960; 2: 1-4.

Mills WJ, Whaley R, Fish W. Frostbite, II: Experience with rapid rewarming and ultrasonic therapy. Alaska Med. 1960; 2: 114-124.

Mills WJ, Whaley R, Fish W. Frostbite ,III: Experience with rapid rewarming and ultrasonic therapy. Alaska Med. 1961; 3: 28-36.

Mills WJ. Clincial Aspects of Frostbite Injury. In proceedings of the Symposium on Arctic Biology and Medicine. IV, Frostbite. Fort Wainright, Alaska, 1964, Arctic Aeromedical Laboratory.

Mills WJ and Whaley R. Frostbite: Experience with rapid rewarming and ultrasonic therapy. 1960-1. Wilderness and Environ Med 1998; 9: 226-247.

Mills WJ. Clinical Aspects of Freezing Cold Injury in Medical Aspects of Harsh Environments in the Textbook of Military Medicine. US Surgeon General's Office. 2002. Pp 429-67.

Mizukami H, Shimizu K, Shiono H, Uezono T, Sasaki M. Forensic diagnosis of death from cold. Legal Med. 1999; 1: 204-209.

Molnar GW. Survival of hypothermia by men immersed in the ocean. JAMA 131:1046, 1946.

Moran DS and Mendal L. Core temperature measurement: methods and current insights. Sports Med. 2002; 32(14): 879-85.

Moritz AR, Henriques FC. Studies of Thermal Injury: II. The Relative Importance of Time and Surface Temperature in the Causation of Cutaneous Burns. Am J Pathol. 1947; 23(5): 695-720.

Mouritzen CV and Anderson MN. Myocardial temperature gradients and ventricular fibrillation during hypothermia. J Thorac Cardiovasc Surg. 1965; 49: 937-44.

Munjal S, Koval T, Muhammad R, Jin Y, Demmel V, Roethig HJ, Mendes P, Unverdorben $M$. Heart rate variability increases with reductions in cigarette smoke exposure after 3 days. J Cardiovasc Pharmacol Ther. 2009; 14(3): 192-8.

Murkin JM. Cerebral autoregulation: the role of $\mathrm{CO} 2$ in metabolic homeostasis. Semin Cardiothorac Vasc Anesth. 2007; 11(4): 269-73. 
Mäkinen TM, Jokelainen J, Näyhä S, Laatikainen T, Jousilahti P, Hassi J. Occurrence of frostbite in the general population--work-related and individual factors. Scand J Work Environ Health. 2009;35(5):384-93.

National Board of Health and Welfare. Patientregistret [homepage on the Internet]. c2012 [cited 2011, Sept 24]. Available from http://www.socialstyrelsen.se/register/halsodataregister/patientregistret

Neil HA, Dawson JA, Baker JE. Risk of hypothermia in elderly patients with diabetes. Br Med J. 1986; 293: 416.

No author. The Estonia disaster - The loss of M/S Estonia in the Baltic on 28th September 1994 - KAMEDO-report 68. Stockholm: Swedish Disaster Medicine Study Organisation at the National Board of Health and Welfare; 1997.

Oberhammer R, Beikircher W, Hörmann C, Lorenz I, Pycha R, Adler-Kastner L, Brugger $H$. Full recovery of an avalanche victim with profound hypothermia and prolonged cardiac arrest treated by extracorporeal re-warming. Resuscitation. 2008; 76(3): 47480 .

O'Brien H, Amess JA, Mollin DL. Recurrent thrombocytopenia, erythroid hypoplasia, and sideroblastic anaemia associated with hypothermia. Br J Haematol. 1982; 51(3): 451-6.

O'Connor JP. Use of peritoneal dialysis in severely hypothermic patients. Ann Emerg Med. $1986 ; 15(1): 104-5$.

Osczevski RJ. The basis of wind chill. Arctic 1995; 48: 372.

Okada M and Nishimura F. Respiratory function and acid-base status in accidental hypothermia.assessed by arterial blood gas analysis. Jpn J Med. 1990; 29: 500-5.

Paton BC. Accidental hypothermia. Pharmacol Ther. 1983 ; 22: 331.

Paton BC. Excerpts from: measurements of dry atmospheric cooling in subfreezing temperatures. 1945. Siple PA, Passel CF. Wilderness Environ Med. 1999; 10(3): 17682.

Patt A, McCroskey BL, Moore EE. Hypothermia-induced coagulopathies in trauma. Surg Clin North Am. 1988; 68(4): 775-85.

Peristein PH, Hersh C, Glueck CJ, Sutherland JM. Adaption to cold in the first three days of life. Pediatrics. 1974; 54: 411.

Pina-Cabral JM, Ribeiro-da-Silva A, Almeida-Dias A. Platelet sequestration during hypothermia in dogs treated with sulphinpyrazone and ticlopidine: reversibility accelerated after intra-abdominal rewarming. Thromb Haemost. 1985; 54(4): 838-41.

Pledger HG. Disorders of temperature regulation in acute traumatic tetraplegia. J Bone Joint Surg. 1963; 44: 110.

Radwin MI, Grissom CK, Giesbrecht G. The rate of cooling during avalanche burial; a "core" issue. Resuscitation. 2009; 80(8): 956-7.

Rahn H, Reeves RB, Howell BJ. Hydrogen ion regulation, temperature, and evolution. Am Rev Respir Dis. 1975; 112(2): 165-72.

Rahn H. Body temperature and acid-base regulation. Pneumonologie. 1974; 151(2): 87-94.

Ream AK, Reitz BA, Silverberg G. Temperature correction of $\mathrm{PaCO} 2$ and $\mathrm{pH}$ in estimating acid-base status: an example of emperor's new clothes? Anesthesiology. 1982; 56(1): 41-4. 
Reed RL 2nd, Bracey AW Jr, Hudson JD, Miller TA, Fischer RP. Hypothermia and blood coagulation: dissociation between enzyme activity and clotting factor levels. Circ Shock. 1990; 32: 141-52.

Reed RL 2nd, Johnson TD, Hudson JD, Fischer RP The disparity between hypothermic coagulopathy and clotting studies. J Trauma. 1992; 33: 465-70.

Reuler JB, Jones SR, Girard DE. Hypothermia in the erythroderma syndrome. West J Med. 1977; 127: 243.

Reuler JB and Parker RA. Peritoneal dialysis in the management of hypothermia. JAMA. 1978; 240(21): 2289-90.

Reuler JB. Hypothermia: pathophysiology, clinical settings, and management. Ann Intern Med. 1978: 89: 519-27.

Rintamäki H. Human responses to cold. Alaska Med. 2007: 49 (2 Suppl): 29-31,.

Robinson M and Seward PN. Environmental hypothermia in children. Pediatr Emerg Care. 1986; 2: 254-7.

Robson MC, Heggers JP. Evaluation of hand frostbite blister fluid as a clue to pathogenesis. J Hand Surg Am. 1981; 6(1): 43-7.

Rosenkrantz L. Bone marrow failure and pancytopenia in two patients with hypothermia. South Med J. 1985; 78(3): 358-9.

Rural National Program for Sweden 2007-2013. Swedish Government Report, Department of Agriculture. 2009, Stockholm, Sweden. [cited 2011 Sept 30] Available from: http://www.regeringen.se/sb/d/10158/a/82727.

Ruttmann E, Weissenbacher A, Ulmer H, Müller L, Höfer D, Kilo J, Rabl W, Schwarz B, Laufer G, Antretter H, Mair P. Prolonged extracorporeal membrane oxygenationassisted support provides improved survival in hypothermic patients with cardiocirculatory arrest. J Thorac Cardiovasc Surg. 2007; 134(3): 594-600.

Röggla M, Frossard M, Wagner A, Holzer M, Bur A, Röggla G. Severe accidental hypothermia with or without hemodynamic instability: rewarming without the use of extracorporeal circulation. Wien Klin Wochenschr. 2002; 114(8-9): 315-20.

Saemi AM, Johnson JM, Morris CS. Treatment of bilateral hand frostbite using transcatheter arterial thrombolysis after papaverine infusion. Cardiovasc Intervent Radiol. 2009; 32(6): 1280-3.

Saukko P, Knight B. Knight's Forensic Pathology. $3^{\text {rd }}$ ed. Arnold Publication: London; 2004.

Shenaq SA, Yawn DH, Saleem A, Joswiak R, Crawford ES. Effect of profound hypothermia on leukocytes and platelets. Ann Clin Lab Sci. 1986; 16(2): 130-3.

Sheridan RL, Goldstein MA, Stoddard FJ Jr, Walker TG. Case records of the Massachusetts General Hospital. Case 41-2009. A 16-year-old boy with hypothermia and frostbite. N Engl J Med. 2009; 361(27): 2654-62.

Shitzer A. Wind-chill-equivalent temperatures: regarding the impact due to the variability of the environmental convective heat transfer coefficient. Int J Biometeorol. 2006; 50(4): 224-32.

Schuhfried $\mathrm{O}$ and Vacariu G. Thermographic parameters in the diagnosis of secondary Raynaud's phenomenon. Arch Phys Med Rehabil. 2000; 81: 495-9. 
Schrijver G and van der Maten J. Severe accidental hypothermia: pathophysiology and therapeutic options for hospitals without cardiopulmonary bypass equipment. Neth J Med. 1996; 49(4): 167-76.

Shattock MJ and Tipton MJ. 'Autonomic Conflict': a different way to die during cold water immersion? J Physiol. 2012 Apr 30. [Epub ahead of print]

Sinet M, Muffat-Joly M, Bendaace T, Pocidalo JJ. Maintaining blood $\mathrm{pH}$ at 7.4 during hypothermia has no significant effect on work of the isolated rat heart. Anesthesiology. 1985; 62: 582-7.

Siple P and Passel CF. Measurements of dry atmospheric cooling in subfreezing temperatures. Proc Am Philosoph Soc. 1945; 89: 177.

Snider RL and Porter JM. Treatment of experimental frostbite with intra-arterial sympathetic blocking drugs. Surgery. 1975; 77(4): 557-61.

Soar J, Perkins GD, Abbas G, Alfonzo A, Barelli A, Bierens JJ, Brugger H, Deakin CD, Dunning J, Georgiou M, Handley AJ, Lockey DJ, Paal P, Sandroni C, Thies KC, Zideman DA, Nolan JP. European Resuscitation Council Guidelines for Resuscitation 2010 Section 8. Cardiac arrest in special circumstances: Electrolyte abnormalities, poisoning, drowning, accidental hypothermia, hyperthermia, asthma, anaphylaxis, cardiac surgery, trauma, pregnancy, electrocution. Resuscitation. 2010; 81(10): 140033.

Southwick FS and Dalglish RH. Recovery after prolonged hypothermia. JAMA. 1980; 243: 1250-3.

Spelman E. Xenophon: The Expedition of Cyrus into Persia, and the Retreat of Ten Thousand Greeks, 400 B.C. Translated, Esq. (2 vols). London. 1749 D. Brown et al.

Steinman AM. Cardiopulmonary resuscitation and hypothermia. Circulation. 1986; 74: (suppl IV) 29-32.

Steinman A. Prehospital management of hypothermia. Response. 1987; 6: 18.

Stiff RE, Morris-Stiff GJ, Torkington J. Hypothermia and acute pancreatitis: myth or reality? J R Soc Med. 2003; 96(5): 228-9.

Swain JA, White FN, Peters RM. The effect of $\mathrm{pH}$ on the hypothermic ventricular fibrillation threshold. J Thorac Cardiovasc Surg 87:445-51, 1984.

Swan H, Zeavin I, Holmes JH, Montgomery V. Cessation of circulation in general hypothermia. I. Physiologic changes and their control. Ann Surg. 1953; 138: 360-76.

Swartz RD, Fitzgerald FT, Kalousdian S, Budd M. Hypothermia in the uremic patient. Dialysis Transplant. 1983; 12: 584-90.

Takada M, Kusano I, Yamamoto H, Shiraishi T, Yatani R, Haba K. Wischnevsky's gastric lesions in accidental hypothermia. Am J Forensic Med Pathol. 1991; 12(4): 300-5.

Tanaka $\mathrm{M}$ and Tokudome $\mathrm{S}$. Accidental hypothermia and death from cold in urban areas. Int J Biometeorol. 1991; 34(4): 242-6.

Task Force of The European Society of Cardiology and The North American Society of Pacing and Electrophysiology. Heart rate variability: Guidelines, Standards of measurement, physiological interpretation, and clinical use. European Heart Journal. 1996; 17: 354-381. 
Tikuisis P. Predicting survival times at sea based on observed body cooling rates. Aviat Space and Environ Med. 1997; 68: 441.

Tipton M, Eglin C, Gennser M, Golden F. Immersion deaths and deterioration in swimming performance in cold water. Lancet. 1999; 354: 626-9.

Turk EE. Hypothermia. Forensic Sci Med Pathol. 2010; 6(2): 106-115.

Urschel JD, Urschel JW, Mackenzie WC. The role of alcohol in frostbite injury. Scand J Soc Med. 1990; 18(4): 273.

Vanggaard L, Eyolfson D, Xu X, Weseen G, Giesbrecht GG. Immersion of distal arms and legs in warm water (AVA rewarming) effectively rewarms mildly hypothermic humans. Aviat Space Environ Med. 1999; 70(11): 1081-8.

Vandam LD and Burnap TK. Hypothermia. N Engl J Med. 1959; 261: 596-603.

Valeri CR, Feingold H, Cassidy G, Ragno G, Khuri S, Altschule MD. Hypothermiainduced reversible platelet dysfunction. Ann Surg. 1987; 205(2): 175-81.

von Bierbrauer A, Schilk I, Lucke C, Schmidt JA. Infrared thermography in the diagnosis of Raynaud's phenomenon in vibration-induced white finger. Vasa. 1998; 27: 94- 9.

von Heimburg D, Noah EM, Sieckmann UP, Pallua N. Hyperbaric oxygen treatment in deep frostbite of both hands in a boy. Burns. 2001; 27(4): 404-8.

Walpoth BH, Galdikas J, Leupi F, Muehlemann W, Schlaepfer P, Althaus U. Assessment of hypothermia with a new "tympanic" thermometer. J Clin Monit. 1994; 10(2): 91-6.

Walpoth BH, Walpoth-Aslan BN, Mattle HP, Radanov BP, Schroth G, Schaeffler L, Fischer AP, von Segesser L, Althaus U. Outcome of survivors of accidental deep hypothermia and circulatory arrest treated with extracorporeal blood warming. N Engl J Med. 1997; 337: 1500-5.

Webb GE. Comparison of esophageal and tympanic temperature monitoring during cardiopulmonary bypass. Anesth Analg. 1973; 52: 729-33.

Wedin B, Vanggard L, Hirvonen J. "Paradoxical undressing" in fatal hypothermia. J Forensic Sci. 1979; 24: 543-53.

Weinberg AD, Hamlet MP, Paturas JL, White RD, McAninch G. Cold water emergencies: principles of patient management. American Medical Publishing Co: Branford, CN; 1990.

Westin B, Sehgal N, Assali NS. Regional blood flow and vascular resistance during hypothermia in dogs. Am J Physiol 1961; 201: 485-91.

Wilkerson J and Hamlet MP. Medical after action conference, Mount Hood, 1986, bypass rewarming. US Army Research Institute of Environmental Medicine, 1988.

Wissler EH. Probability of survival during accidental immersion in cold water. Aviat Space Environ Med. 2003; 74(1): 47-55.

Wong FW. J wave and hypothermia, Dynamics. 2005; 16(4): 17-8.

World Health Organisation. International Classification of Diseases (ICD-10). [cited 2012 April 26], [Homepage on the Internet] c2012. Available from http://www.who.int/classifications/icd/en/ .

Young AJ. Effects of aging on human cold tolerance. Exp Aging Res. 1991; 17: 205. 
Zell SC and Kurtz KJ. Severe exposure hypothermia: a resuscitation protocol. Ann Emerg Med. 1985; 14(4): 339-45. 